\title{
Snow Ensemble Uncertainty Project (SEUP): quantification of snow water equivalent uncertainty across North America via ensemble land surface modeling
}

\author{
Rhae Sung Kim ${ }^{1,2}$, Sujay Kumar ${ }^{1}$, Carrie Vuyovich ${ }^{1}$, Paul Houser ${ }^{3}$, Jessica Lundquist ${ }^{4}$, Lawrence Mudryk ${ }^{5}$, \\ Michael Durand $^{6}$, Ana Barros ${ }^{7}$, Edward J. Kim ${ }^{1}$, Barton A. Forman ${ }^{8}$, Ethan D. Gutmann ${ }^{9}$, Melissa L. Wrzesien ${ }^{1,2}$, \\ Camille Garnaud $^{10}$, Melody Sandells ${ }^{11}$, Hans-Peter Marshall ${ }^{12}$, Nicoleta Cristea ${ }^{4}$, Justin M. Pflug ${ }^{4}$, \\ Jeremy Johnston ${ }^{3}$, Yueqian Cao ${ }^{7}$, David Mocko ${ }^{1,13}$, and Shugong Wang ${ }^{1,13}$ \\ ${ }^{1}$ Hydrological Sciences Laboratory, NASA Goddard Space Flight Center, Greenbelt, MD, USA \\ ${ }^{2}$ Universities Space Research Association, Columbia, MD, USA \\ ${ }^{3}$ Department of Geography and Geoinformation Sciences, George Mason University, Fairfax, VA, USA \\ ${ }^{4}$ Civil and Environmental Engineering, University of Washington, Seattle, WA, USA \\ ${ }^{5}$ Climate Research Division, Environment and Climate Change Canada, Toronto, Ontario, Canada \\ ${ }^{6}$ School of Earth Sciences and Byrd Polar and Climate Research Center, The Ohio State University, Columbus, OH, USA \\ ${ }^{7}$ Department of Civil and Environmental Engineering, University of Illinois at Urbana-Champaign, Champaign, IL, USA \\ ${ }^{8}$ Civil and Environmental Engineering, University of Maryland, College Park, MD, USA \\ ${ }^{9}$ National Center for Atmospheric Research, Boulder, Colorado, USA \\ ${ }^{10}$ Meteorological Research Division, Environment and Climate Change Canada, Dorval, Quebec, Canada \\ ${ }^{11}$ Geography and Environmental Sciences, Northumbria University, Newcastle upon Tyne, UK \\ ${ }^{12}$ Department of Geosciences, Boise State University, Boise, ID, USA \\ ${ }^{13}$ Science Applications International Corporation, Reston, VA, USA
}

Correspondence: Rhae Sung Kim (rhaesung.kim@ nasa.gov)

Received: 26 August 2020 - Discussion started: 15 September 2020

Revised: 15 December 2020 - Accepted: 3 January 2021 - Published: 17 February 2021

\begin{abstract}
The Snow Ensemble Uncertainty Project (SEUP) is an effort to establish a baseline characterization of snow water equivalent (SWE) uncertainty across North America with the goal of informing global snow observational needs. An ensemble-based modeling approach, encompassing a suite of current operational models is used to assess the uncertainty in SWE and total snow storage (SWS) estimation over North America during the 2009-2017 period. The highest modeled SWE uncertainty is observed in mountainous regions, likely due to the relatively deep snow, forcing uncertainties, and variability between the different models in resolving the snow processes over complex terrain. This highlights a need for high-resolution observations in mountains to capture the high spatial SWE variability. The greatest SWS is found in Tundra regions where, even though the spatiotemporal variability in modeled SWE is low, there is considerable
\end{abstract}

uncertainty in the SWS estimates due to the large areal extent over which those estimates are spread. This highlights the need for high accuracy in snow estimations across the Tundra. In midlatitude boreal forests, large uncertainties in both SWE and SWS indicate that vegetation-snow impacts are a critical area where focused improvements to modeled snow estimation efforts need to be made. Finally, the SEUP results indicate that SWE uncertainty is driving runoff uncertainty, and measurements may be beneficial in reducing uncertainty in SWE and runoff, during the melt season at high latitudes (e.g., Tundra and Taiga regions) and in the western mountain regions, whereas observations at (or near) peak SWE accumulation are more helpful over the midlatitudes. 


\section{Introduction}

Seasonal snow plays an important role in Earth's climate and ecological systems and influences the number of water resources available for agriculture, hydropower, and human consumption, serving as the primary freshwater supply for more than a billion people worldwide (Foster et al., 2011). There is a critical need to better understand the role of snow in global climate and land-atmosphere interactions (Brooks et al., 2011; Robinson and Kukla, 1985; Stielstra et al., 2015) and associated influences on soil moisture, vegetation health, and streamflow (Berghuijs et al., 2014; Ryberg et al., 2016; Stewart et al., 2005). Decreases in total snow water storage can lead to increased droughts (Barnett et al., 2005; Fyfe et al., 2017; Mahanama et al., 2012) and wildfires (Westerling et al., 2006). In addition, snowmelt is a dominant driver of flooding in many regions of the United States (Berghuijs et al., 2016).

Though accurate and timely estimates of snow water equivalent (SWE) are required for water and ecosystem management, obtaining reliable, spatially distributed SWE has been a challenge, particularly at continental and global scales. At these scales, satellite observations are ideal, but global SWE observations remain a major gap in snow remote sensing (Dietz et al., 2012; Lettenmaier et al., 2015; Nolin, 2010), and the US National Research Council committees of the Decadal Survey (National Academies of Sciences, Engineering, and Medicine, 2018) identify SWE as a missing component of spaceborne water cycle measurements. This has motivated the advancement of models and remote sensing techniques to estimate global snow characteristics (e.g., NASA SnowEx; Durand et al., 2019; Kim et al., 2017). Developing the necessary observational methods for global coverage while also supporting local snow applications is a significant challenge facing the snow community (Dozier et al., 2016; Lettenmaier et al., 2015). Both models and remote sensing techniques are impacted by numerous factors, resulting in significant spatial or temporal errors in SWE estimation.

A potential solution to reduce uncertainty associated with any single technique is to combine models and remote sensing in a data assimilation framework, but this requires an understanding of the underlying uncertainty to be employed. In this study, called the Snow Ensemble Uncertainty Project (SEUP), we apply an ensemble-based land surface modeling approach to establish a baseline characterization of SWE and its corresponding uncertainty across North America. The term "SWE uncertainty" used in this study will refer to the range of SWE estimates across models and is quantified as the ensemble spread. Compared to the use of a single model realization, ensemble modeling is generally considered a better approach to characterize the inherent uncertainties in modeling, with the ensemble spread providing a measure of the uncertainty in the predictions across models and forcing data (Bohn et al., 2010; Dirmeyer et al., 2006; Franz et al., 2008; Guo et al., 2007; Kumar et al., 2017; Mitchell et al., 2004; Mudryk et al., 2015; Murphy et al., 2004; Xia et al., 2012). An ensemble evaluation can also lead to increased skill by combining a variety of model estimates and allowing the individual model errors to cancel each other out (Xia et al., 2012). We use the ensemble SWE estimates to assess the general spatial and temporal North American SWE characteristics.

The SEUP ensemble is comprised of 12 ensemble members, created by the combination of four different land surface models (LSMs) and three different forcing datasets. By using a mix of different LSMs and boundary conditions, the SEUP ensemble captures the uncertainties from both these sources. The design of the SEUP ensemble is focused on current snow capabilities in macroscale modeling, as the land models and forcing datasets selected here represent models and datasets currently being employed at key operational centers and systems (described in Sect. 2.2). The designed experiment is conducted at a $5 \mathrm{~km}$ spatial resolution for multiple winter snow seasons (2009-2017). By using a range of forcing products and commonly used operational models, we assume that the SEUP ensemble implicitly provides a representation of both sources of uncertainty. It is likely, however, that the SEUP ensemble may be deficient in representing the true uncertainty, given the possible errors in boundary conditions, model parameters, and model structure. Nevertheless, the SEUP ensemble establishes an important baseline over the continental scales to characterize current capabilities and inform global snow observational requirements. Toward this goal, in this article we strive to address several gaps in our current understanding of SWE uncertainty with our simulation of snow states over the North American continental domain, including the following questions. (1) Where are the areas of significant uncertainty in SWE? (2) What is the seasonality of SWE uncertainty and its spatial distribution? (3) How does uncertainty in SWE vary with key land surface characteristics such as vegetation, topography, and snow climate? (4) How do these regions of high SWE uncertainty correlate with runoff uncertainties?

The paper is organized as follows: Sect. 2.1 introduces the study area and time period, followed by the descriptions of the LSMs and forcing datasets used in this study in Sect. 2.2 and 2.3, respectively. Section 2.4 provides the details about the experimental design, ensemble-based methods, and datasets used in the uncertainty evaluation. An evaluation of the SEUP ensemble against a number of reference products is presented in Sect. 3.1. Section 3.2 provides the results of SWE uncertainty analysis over North America. The influence of factors such as topography, snow regime, and vegetation type on snow water equivalent/total snow water storage (SWE/SWS) uncertainty is examined in Sect. 3.3. Section 3.4 discusses how the snow modeling uncertainty impacts the uncertainty in the terrestrial water budget components. Finally, Sect. 4 provides the major findings and conclusions of this effort. 


\section{Study area and ensemble configuration}

\subsection{Study area and time period}

The study area is the North American continental domain consisting of a $0.05^{\circ}$ latitude by $0.05^{\circ}$ longitude equidistant cylindrical grid that extends from 24.875 to $71.875^{\circ} \mathrm{N}$ and 168.625 to $51.875^{\circ} \mathrm{W}$ (Fig. 1a). The glacier regions are excluded from the study domain as the representations of glacier processes are limited in the LSMs used here. These glacier exclusions are developed using the Global Land Ice Measurement from Space (GLIMS) geospatial glacier database (Raup et al., 2007). The model integrations and analyses are performed from 2000 to 2017, with the first 9 years (2000-2009) used as a model spin-up to initialize the model's thermal and hydraulic equilibrium states.

\subsection{Land surface models (LSMs)}

The National Aeronautics and Space Administration (NASA) Land Information System (LIS; Kumar et al., 2006; Peters-Lidard et al., 2007) is a comprehensive terrestrial modeling infrastructure designed to facilitate the efficient use and assimilation of terrestrial observations. This study uses a modeling configuration within the NASA LIS that employs four different land surface models (LSMs) of varying complexity at a $5 \mathrm{~km}$ spatial resolution over North America: (1) Noah version 2.7.1 (Noah2.7.1; Ek et al., 2003), (2) Noah-MP version 3.6 (Noah-MP3.6; Niu et al., 2011; Yang et al., 2011), (3) Catchment LSM-Fortuna 2.5 (CLSMF2.5; Ducharne et al., 2000; Koster et al., 2000), and (4) Joint UK Land Environment Simulator (JULES, Best et al., 2011; Blyth et al., 2006; Clark et al., 2011). These models are selected because all are used operationally at major modeling centers - e.g., Noah2.7.1 is used at the US National Centers for Environmental Prediction (NCEP), Noah-MP3.6 at the National Water Model (NWM), CLSM-F2.5 at the NASA Global Modeling and Assimilation Office (GMAO), and JULES at the United Kingdom Met Office (UKMO) - to provide a baseline of current operational capabilities. Note that some of these models do not necessarily represent the state-of-the-art approaches for snow modeling, and their underlying parameterizations may share a similar legacy in terms of code development. Despite these limitations, however, these models and their versions are representative of systems that provide publicly available snow estimates over continental and global scales. Though the outputs from these models are used widely for a variety of water resource management applications, only a few studies have conducted a careful examination of their differences and limitations, particularly over continental spatial scales.

All four LSMs are able to dynamically predict land surface water and energy fluxes in response to surface meteorological forcing inputs, but they differ in their structural representation of surface and subsurface water, as well as energy balance processes. As most land surface models were originally developed to provide the lower boundary conditions for global atmospheric models, their applicability is largely assumed to be at coarse spatial scales where the influence of lateral interactions is negligible. Consequently, similar to other model physics components, the snow physics schemes in these models are not designed to resolve processes at fine spatial scales (e.g., $<100 \mathrm{~m}$ ), such as the influence of blowing and drifting snow. Further, the complexity of snow metamorphic process representation varies across these models. The snow schemes used in this analysis range from a simple single-layer scheme in both Noah2.7.1 and JULES to three-layer intermediate complexity schemes in both NoahMP3.6 and CLSM-F2.5, which greatly influence the snowpack thermodynamics and the resulting timing and presence of melt (Dutra et al., 2011). Note that the UKMO currently uses a three-layer scheme in JULES, which was not available in NASA LIS at the time this study was devised. In order to assess current configurations, initial model conditions and model parameters used in the operational set-up were not tuned in this study (Best et al., 2011; Blyth et al., 2006; Clark et al., 2011; Ducharne et al., 2000; Ek et al., 2003; Koster et al., 2000; Niu et al., 2011; Yang et al., 2011). The key details of the model configurations with forcing datasets are summarized in Table S1 in the Supplement.

\subsection{Forcing datasets}

Three different modern forcing datasets are used to drive the models: (1) Modern-Era Retrospective Analysis for Research and Applications, version 2 (MERRA2; Gelaro et al., 2017; Molod et al., 2015), (2) Global Data Assimilation System (GDAS; Derber et al., 1991), and (3) European Centre for Medium-Range Weather Forecasts (ECMWF; Molteni et al., 1996). Original spatial and temporal resolutions for these datasets are described in Sect. S2. All models are run at $15 \mathrm{~min}$ time intervals. To improve the spatial representativeness of the coarse-resolution meteorological inputs, the input forcing fields were downscaled to a $5 \mathrm{~km}$ grid as follows. Meteorological inputs of near-surface air temperature, relative humidity, surface pressure, and downward longwave radiation are downscaled by applying a lapse-rate and hypsometric adjustments using the $5 \mathrm{~km}$ Shuttle Radar Topography Mission (SRTM; south of $60^{\circ} \mathrm{N}$ ) and the USGS Global 30 arcsec elevation (GTOPO30; north of $60^{\circ} \mathrm{N}$ ) datasets. The lapse-rate correction method follows the approach used in the North American Land Data Assimilation System (NLDAS)1 and 2 projects (Cosgrove et al., 2003) where a static environmental lapse rate of $6.5 \mathrm{~K} \mathrm{~km}^{-1}$ is used to apply an elevation adjustment to the coarse meteorological fields. The downwelling shortwave radiation fields are downscaled using terrain characteristics of slope and aspect as described in Kumar et al. (2013). Over the east- and west-facing slopes, the slope and aspect-based corrections lead to improvements to diurnal processes. Kumar et al. (2013) demonstrated that 
(a)

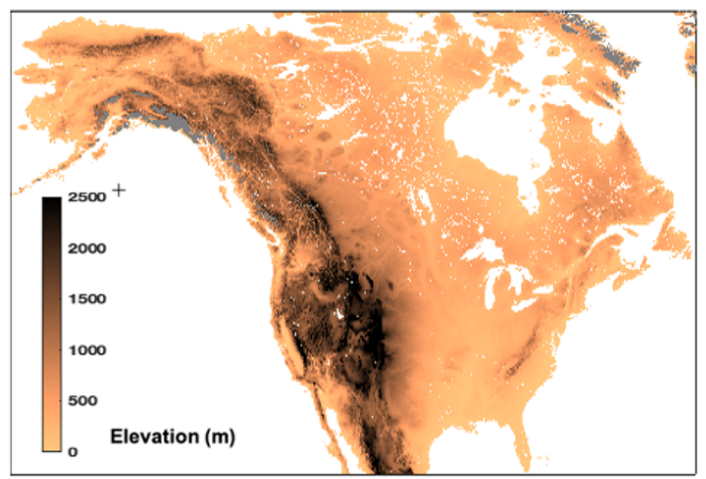

(c)

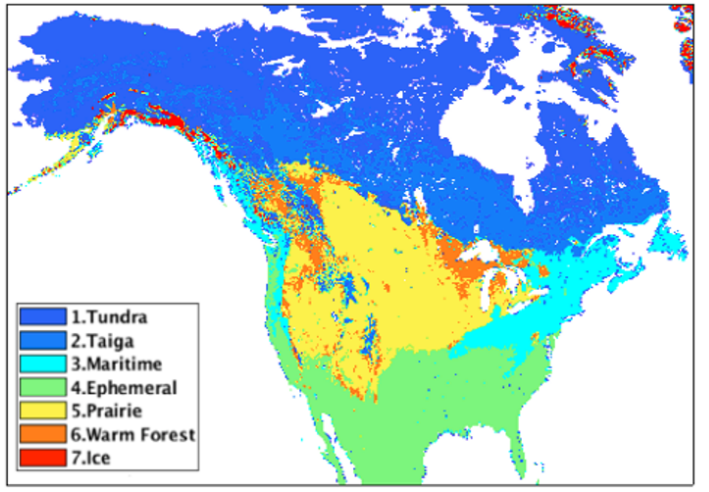

(b)

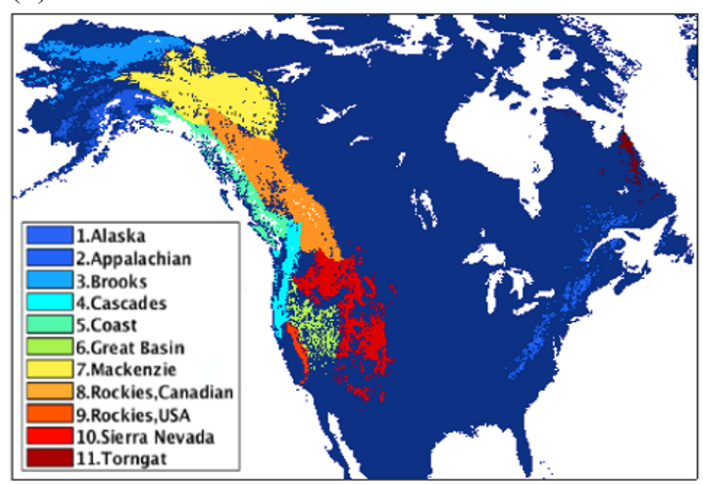

(d)

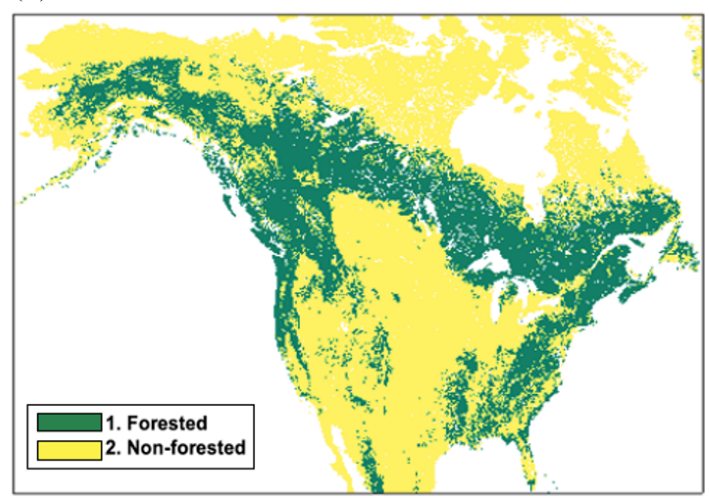

Figure 1. Snow Ensemble Uncertainty Project (SEUP) domain: (a) domain with terrain elevation (gray areas indicate the excluded glacier regions), (b) individual mountain domains, (c) individual snow class domains, and (d) land cover classification used in this study.

these adjustments are particularly important for improving snow simulations over midlatitude domains in complex topography and concluded that these adjustments should be included in models with resolutions finer than $16 \mathrm{~km}$, but the adjustments are likely to be small at $5 \mathrm{~km}$ resolution. The precipitation fields are downscaled using a variant of the scaling approach of Lenderink et al. (2007) with the high-resolution monthly precipitation climatology dataset, WorldClim (Fick and Hijmans, 2017). The downscaling is performed by fixing the ratio of high-resolution precipitation climatology to that of the same climatology at the coarser-scale resolution in order to maintain the heterogeneity of the precipitation forcing fields. The three global datasets are all derived using global atmospheric models that assimilate a large collection of surface and atmospheric observations and differ primarily in the atmospheric model and assimilation system used.

\subsection{Methods}

\subsubsection{SEUP ensemble evaluation methods}

We use two metrics to evaluate the SEUP ensemble: (1) ensemble rank (ER), which ranks the observation relative to the ensemble providing a measure of how well the ensemble encompasses a reference observation; and (2) continuous rank probability score (CRPS; Matheson and Winkler, 1976), which measures the difference between the model and the reference distributions. For computing ER, the ensemble is first organized in the following order: CLSM-F2.5 (ensemble members 1 to 3), JULES (4 to 6), Noah-MP3.6 (7 to 9), and Noah2.7.1 (10 to 12), with the order within each LSM being the runs forced with ECMWF, GDAS, and MERRA2 data, respectively. The ensemble SWE at each grid point and each temporal instance is then sorted and ordered first. The rank of the reference data within this sorted array is then used as the ER. If the observation is more than $10 \%$ higher than the highest ensemble member, then the rank is set to 13 . As a demonstrative example, if the ensemble SWE values are 1, $3,7,2,4,5,6,1,3,8,1,0$ units and the observation has a value of 5 units, the ER of the observation is set to 9 as the sorted array will be $0,1,1,1,2,3,3,4,5,6,7,8$. Note that the main objective of the ER metric is to examine whether the ensemble encompasses the reference data.

CRPS is an often-used performance measure in probabilistic forecasting, computed using Eq. (1). It provides a measure of the degree of difference between the model distribution and the observation. CRPS reduces to the mean absolute error when used with deterministic (single-member) ensembles. 
CRPS $=\int_{-\infty}^{+\infty}\left(P_{\mathrm{m}}-P_{\mathrm{o}}\right)^{2} \mathrm{~d} x$,

where $P_{\mathrm{m}}$ represents the cumulative distribution function (CDF) of the model and $P_{\mathrm{o}}$ represents the Heaviside step function at the observed value. Note that the SEUP ensemble size (12) is relatively small, which may affect the resolution of the CDF derived from it. Nevertheless, CRPS provides an integrated way of capturing the error associated with the SEUP ensemble when compared to reference measurements, where a low (good) score indicates a small ensemble spread that encompasses the reference observation and a high (bad) score indicates a large spread and/or large difference from the observation.

\subsubsection{Reference and ancillary datasets used in the uncertainty evaluation}

The reference datasets used for evaluation in SEUP are (1) the daily, gridded snow depth, and SWE analysis from the NOAA National Weather Service's National Operational Hydrologic Remote Sensing Center (NOHRSC) Snow Data Assimilation System (SNODAS; Barrett, 2003) available at 30 arcsec spatial resolution; (2) daily gridded estimates of snow depth and SWE developed by the University of Arizona (UA; Zeng et al., 2018) available at $4 \mathrm{~km}$ spatial resolution; and (3) the daily, gridded snow depth analysis from the Canadian Meteorological Centre (CMC; Brown and Brasnett, 2010) available at $25 \mathrm{~km}$ spatial resolution. All three datasets are model-based, but they incorporate in situ measurements from various ground networks. SNODAS analyses also encompass satellite and airborne measurements, meteorological aviation reports, and special aviation reports from the World Meteorological Organization (WMO). Though these data are subject to errors, this product provides a consistent, spatially distributed estimate of snowpack conditions throughout the United States and has been used as a comparison dataset in numerous studies (Guan et al., 2013; Meromy et al., 2013; Vuyovich et al., 2014). The UA analysis is developed using an empirical temperature index snow model with data from networks such as the National Resources Conservation Service's SNOTEL and the National Weather Service's Cooperative Observer Program (COOP). The dataset was developed to provide a high-resolution, long-term snow mass product for use in assessing climate change impacts (Zeng et al., 2018). SNODAS and UA datasets are available only over the continental United States, whereas the CMC data are used for snow evaluation over the entire domain. While the CMC data have been frequently used for LSM evaluation (Forman et al., 2012; Reichle et al., 2017; Takala et al., 2011), and have been shown to capture interannual variability well (Brown et al., 2018), several studies have provided evidence that the data underestimate SWE (Dawson et al., 2016; Wrzesien et al., 2017). Despite providing an estimate of SWE, in this analysis, we evaluate the CMC modeled snow depth fields since the CMC only uses snow depth observations in its analysis.

A number of ancillary datasets representing topography, vegetation type, and snow class are used in stratifying the spatial dependence of snow uncertainty. First, to treat mountainous and non-mountainous regions separately in our study, we upscale Wrzesien et al.'s (2018) $1 \mathrm{~km}$ binary mountain mask to our $5 \mathrm{~km}$ grid (see Fig. 1b). Wrzesien et al. (2018) adopted the definition of "mountain" from Kapos et al. (2000) based on the elevation, slope, and local relief. In their work, the mask was divided into 11 individual mountain domains, which we use here to evaluate SEUP results over mountain areas. Table S2 shows the areas of these 11 individual mountain ranges.

An uncertainty analysis on SWE estimation is performed across different snow class regions to understand which regions account for the highest variability. To the best of our knowledge, analyzing uncertainty in SWE estimation across different snow classes at continental scales has not been explored in the literature. In this analysis we use a snow classification at a higher $(10 \mathrm{~km})$ resolution proposed by Liston and Sturm (A global snow classification dataset for Earth-system applications, 2014, unpublished), which analyzes the relationships among textural and stratigraphic characteristics of snow layers, climate variables (e.g., air temperature, precipitation, and wind speed), and vegetation to globally categorize terrestrial snow into seven classes: Tundra, Taiga, Maritime, Ephemeral, Prairie, Warm forest, and Ice. We downscale this global snow classification dataset to our $5 \mathrm{~km}$ model grid (from the native $10 \mathrm{~km}$ spatial resolution). Figure 1c shows the individual domains of seven snow classes over North America, and Table S3 presents their individual areas.

The Moderate Resolution Imaging Spectroradiometer (MODIS)-derived land cover employing the International Geosphere-Biosphere Programme (IGBP) land cover classification method is used to examine the influence of SWE uncertainty to vegetation. For simplicity of comparison, we reclassify the original 17 different land cover classes into two classes. These reclassified land cover classes (i.e., forested vs. non-forested) are displayed in Fig. 1d, and their areas are presented in Table S4.

\section{Results and discussion}

This section presents and discusses results from a range of perspectives. Section 3.1 compares the ensemble with the reference snow datasets. Section 3.2 considers spatial and temporal variation in model uncertainty. Ensemble characteristics are linked to land surface classification in Sect. 3.3. Finally, the impact of model uncertainty on runoff estimation is examined in Sect. 3.4. 


\subsection{Evaluation of the SEUP ensemble}

To evaluate the snow estimates from the SEUP ensemble, three available reference products (described in Sect. 2.4.2) are used. Figure 2 shows maps of average ensemble rank (ER) and average continuous rank probability score (CRPS) (see Sect. 2.4.1) for the SEUP ensemble compared to three reference datasets during the time period of 2009 to 2017. The examination of ER indicates that in general the SEUP ensemble encompasses the three reference measurements. In the SNODAS comparison, ER values larger than 12 can be seen in regions with larger snowpacks, such as the Rockies, indicating that over these areas the SEUP ensemble may be biased low. The ER patterns are similar in both SNODAS and UA comparisons, though the UA comparison shows more spatial variability across different latitudes.

The CRPS comparison provides a measure of the discrepancies between the SEUP ensemble and the reference datasets. Over most of the domain, including the northeast and Midwest United States and high plains, the CRPS values are low $(0-100 \mathrm{~mm})$, where a low (good) score indicates a small ensemble spread that agrees with SNODAS and UA data. As expected, the largest CRPS values are observed over locations with deep snowpacks, such as the Rocky and Pacific coastal mountains, where the SEUP ensemble spread is greatest. Similar but more muted patterns of disagreement are seen with the CMC data compared to SNODAS and UA over mountainous regions, indicating that the SEUP simulations are more consistent with CMC in those areas. In the $\mathrm{CMC}$ comparison, larger errors are also observed at high latitudes, which are likely caused by a combination of larger uncertainties in the boundary conditions and model formulations. Relatively good agreement of SEUP with SNODAS and UA in the ER- and CRPS-based assessments is particularly encouraging, as it provides a measure of confidence that the ensemble encompasses reality.

\subsection{SWE uncertainty analysis}

\subsubsection{Spatial variability of SWE}

An overall assessment of the SWE results is shown in Fig. 3, which presents the spatial distributions of ensemble mean SWE, the coefficient of variation of ensemble mean SWE, and the range of ensemble mean SWE. Because the seasonal timing of the greatest SWE and the largest uncertainty in SWE differ substantially across the North American study domain, we first consider a simple annual mean averaged SWE across the entire time period. Seasonal timing of when the greatest uncertainty occurs is deferred to Sect. 3.2.2. For each pixel, the annual ensemble mean SWE is computed by taking an average of 3-hourly SWE from 12 ensemble members over the entire study time period. We limit the range of coefficient of variation displayed from 0 to 1 (including no- snow time periods in the calculation) for reasons of visual clarity.

The largest spread in ensemble mean SWE is found in regions with the deepest snow (see Fig. 3a and c), particularly along the northern Pacific coastline. Eastern Canada along the northern Atlantic coastline and northern Rocky Mountains also shows a high spread of SWE between ensemble members. These highly complex terrains have relatively high snowfall precipitation, and the large spread is partially due to different rain-snow partitioning schemes in each LSM. While Noah2.7.1, JULES, and CLSM-F2.5 use a simple temperature threshold of $0^{\circ} \mathrm{C}$ to distinguish rainfall and snowfall precipitation, Noah-MP3.6 includes a transition temperature range described in Jordan (1991) (see Table S1). While our lapse-rate correction method is based on approaches used in other products (see Sect. 2.3), the lack of considerations of spatial variability in the snow-rain partition is a limitation, particularly over mountainous areas. Similarly, the spatial distribution of the coefficient of variation shows larger values in areas with the higher ensemble mean SWE and ensemble spread. This indicates that the larger spread is not only due to the larger mean SWE in these areas. In addition, Fig. 3b also shows significant variability across the middle of North America, mostly collocated with boreal forest regions containing denser vegetation, indicating the handling of vegetation on SWE simulations as another source of dissimilarity among the SEUP ensemble members.

\subsubsection{Timing of annual peak SWE}

Figure 4 shows spatial maps of the peak SWE (panel a) and the highest SWE spread (panel b) along with characterizations of the seasonality of the SWE uncertainty (panels c and d). A measure of the spatial variability on the date of the highest SWE uncertainty is determined by computing the day of year (DOY) in each water year with the highest ensemble spread and then averaging DOY across the years to identify the times of high and low uncertainty in SWE over North America. This average DOY of the highest spread is compared with the average DOY of the peak SWE to determine when the largest variability in the SWE spread occurs within the snow season. The DOY with the greatest SWE spread ranges from December-April time frame in the lower latitudes to May-June months in the high latitudes (Fig. 4c). In addition, the seasonality of the greatest SWE uncertainty at higher elevations, such as over the Rocky Mountains and the Pacific coastline, is shifted later in the season as compared to the lower-elevation areas at the same latitude.

The largest SWE spread is along the northern Pacific coastline and eastern Canada along the northern Atlantic coastline (Fig. 4a). If the average DOY with the highest SWE spread matches that of the peak SWE, it suggests that the largest modeling uncertainty occurs in the peak winter time period. From Fig. 4d, we find that DOYs with the highest SWE spread and peak SWE are very close to each other in the 

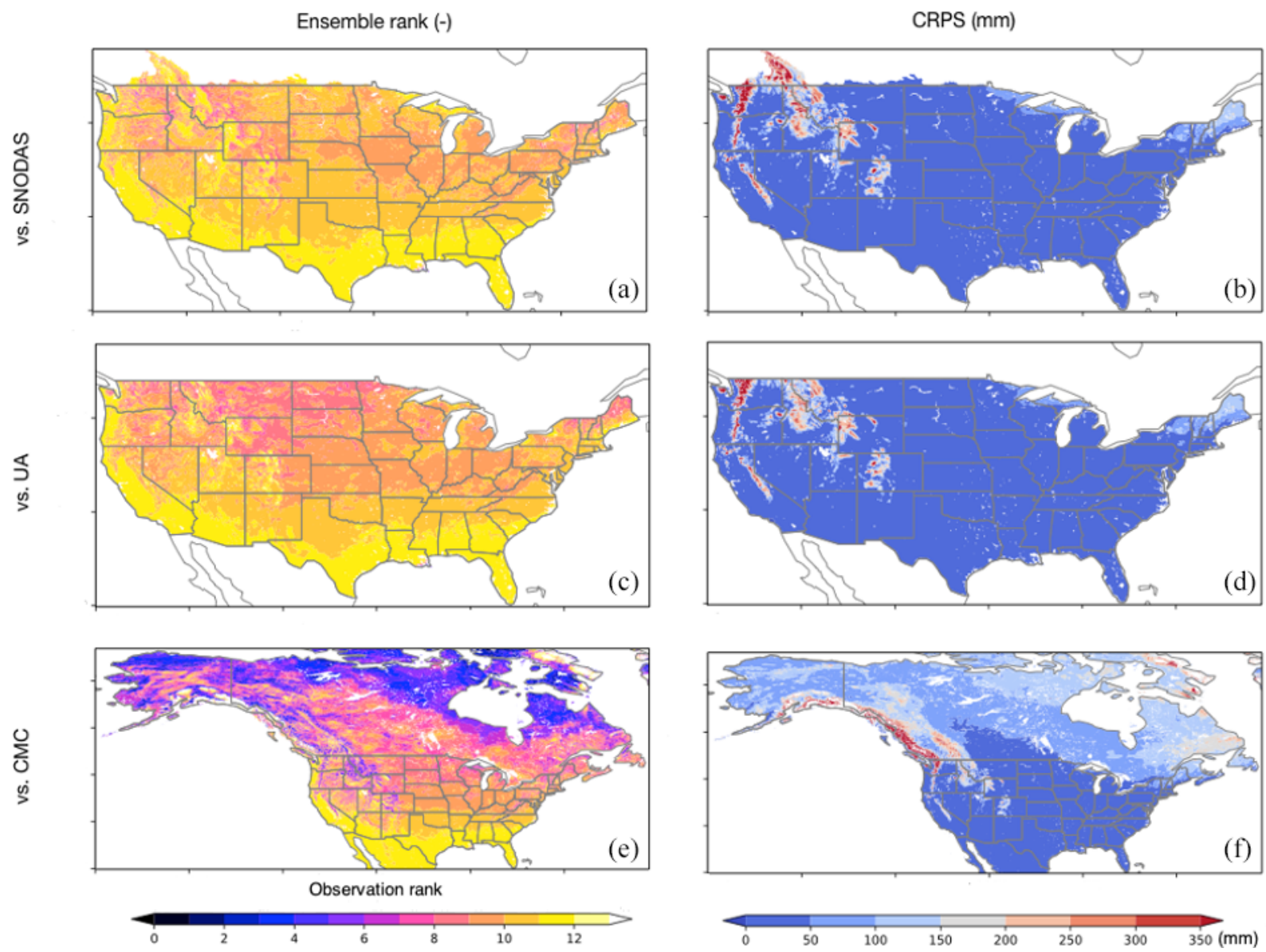

Figure 2. Maps of average ensemble rank (a, c, e) and average continuous rank probability score (CRPS, mm; b, d, f) from the SEUP ensemble compared to SNODAS (a, b), UA (c, d), and CMC (e, f). SWE is used for SNODAS and UA comparisons, whereas snow depth is used for CMC comparison. Ensemble rank represents the rank of the reference data within the SEUP ensemble. Rank 13 represents more snow than all ensembles, and rank 0 is less snow than all ensembles. CRPS, which is the extension of mean absolute error to ensemble evaluation, provides a measure of the degree of agreement between the SEUP ensemble and the reference data.

United States over Canada, and the highest SWE spread has a later DOY than that from the peak SWE, indicating that the largest disagreements in the model estimates are during the melt season. One reason for this could be that the input meteorology has larger differences over high latitudes, whereas over the continental United States they are better constrained due to the greater availability of ground and radar measurements, resulting in better agreement in the determination of snowmelt regimes.

\subsubsection{Interannual variability of SWE}

We compare the time series of domain-averaged daily mean SWE for each ensemble to examine the temporal variability among the ensemble members (Fig. 5). Interestingly, the interannual variability in the peak SWE across the ensemble is small (see Fig. 5), indicating that the simulated total snow water storage in North America as a whole did not change significantly year by year during this time period. Larger spread in the years of 2010 and 2011 are seen when comparing with other years. At a domain-averaged scale, the largest spread in climatological SWE among the ensemble members is seen during the months of February to April and varies by as much as $\sim 60 \%$. In Fig. 5, variability due to model differences (e.g., between solid lines) is generally larger than variability due to forcing data (e.g., between blue lines), consistent with Broxton et al. (2016). Figure S1 shows two time series of domain-averaged daily mean SWE of the Rocky Mountains and the Cascades in the United States (See Fig. 1b and Sect. 3.3.1) where the annual snow behavior is known to be well contrasted (Marshall et al., 2019). In the US Rockies, the spread across the ensemble is smaller, and the annual maximum SWE is relatively unchanged as compared to those of higher elevations in the Cascades. 
(a)

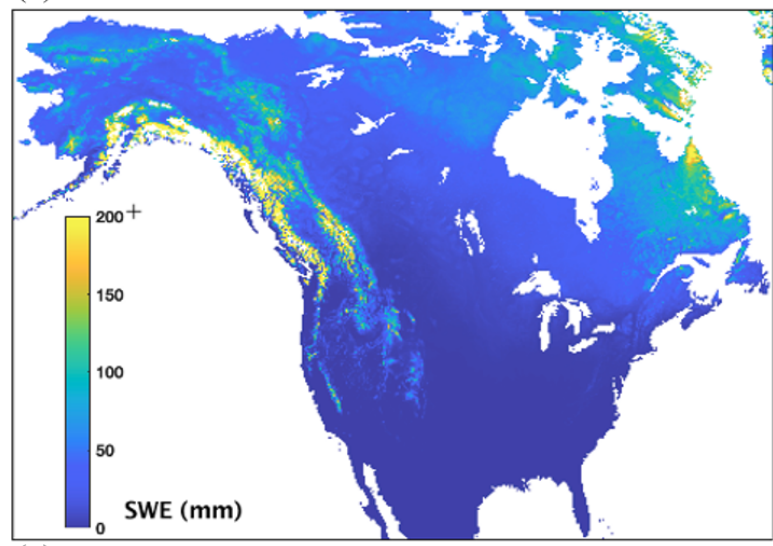

(c) (b)

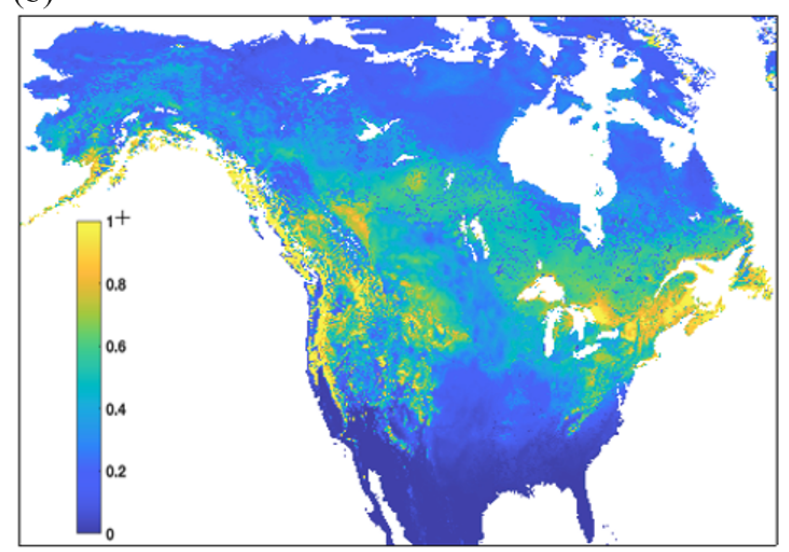

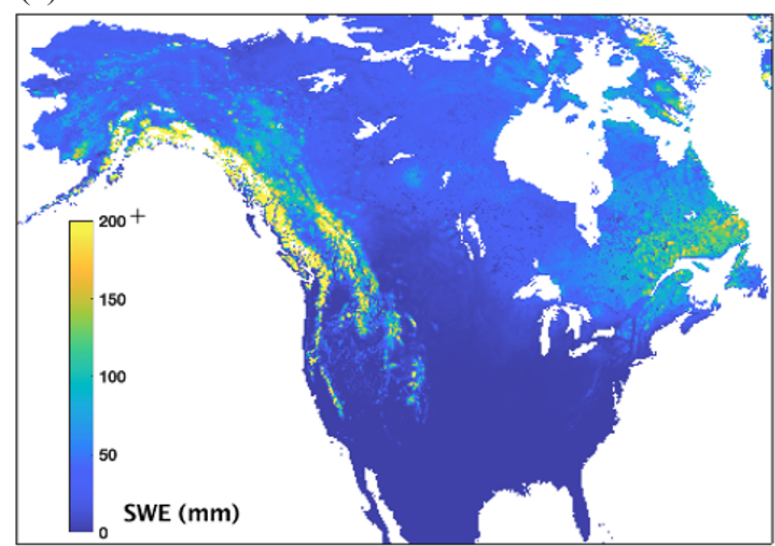

Figure 3. (a) Spatial distributions of ensemble mean SWE, (b) the coefficient of variation of ensemble mean SWE, and (c) the range of ensemble mean SWE. The ensemble mean SWE is computed by taking an average of 3-hourly SWE from 12 ensembles over the entire study time period (from 2009 to 2017).

\subsubsection{Impact between different LSMs and forcing data on SWE uncertainty}

We further examine the influence of models and forcing data on SWE variability by comparing each ensemble grouped by LSMs and forcing data. Figure 6 shows the distribution of domain-averaged, annual mean SWE and indicates that there are smaller differences in SWE across the forcing datasets when driving a common LSM, whereas larger differences are seen across the LSMs when driven with a common forcing data. This finding, from both temporal and spatial analyses, indicates that, within our ensemble set, the dominant factor driving uncertainty in SEUP SWE estimates over North America is from the LSM. This result is consistent with that from Mudryk et al. (2015) using an analogous but more limited ensemble of gridded snow products (cf. Fig. 12 in that paper). Note that both conclusions are based on analysis at the continental or hemispheric scale, and there could be differences at smaller scales and/or in topographically complex regions such as mountainous areas. For example, Raleigh et al. (2016) and Günther et al. (2019) showed the forcing data to be the primary driver of SWE uncertainty in their study, with each using a single forcing dataset with added uncertainty and focused on a limited number of relatively small sites mostly in mountainous terrains. Similarly, Yoon et al. (2019) recently showed that the forcing data drove the uncertainty of model-simulated estimates (i.e., precipitation, evaporation, and runoff) over High Mountain Asia due to significant differences in the quality of reliable reference measurements over the domain. Future efforts should focus on evaluating model parameterizations and snow physics schemes such as sublimation, blowing and drifting snow, and snow-vegetation interactions to identify how representations of snow physical processes are driving the spread.

\subsubsection{Observational needs}

The above results are used to motivate recommendations about the spatial and temporal extent to which satellite snow observations may be beneficial. While additional analysis is needed to understand and improve the model parameterizations that are driving the ensemble spread, remote sensing observations have the potential to reduce uncertainty 
(a)

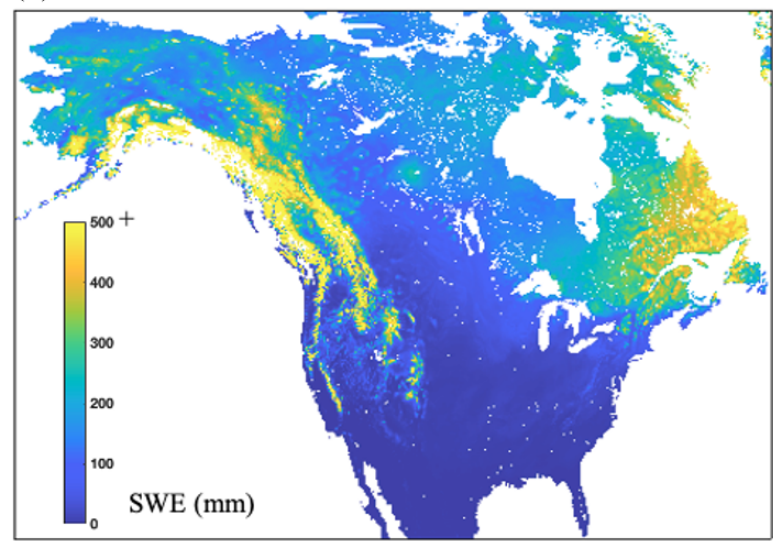

(c)

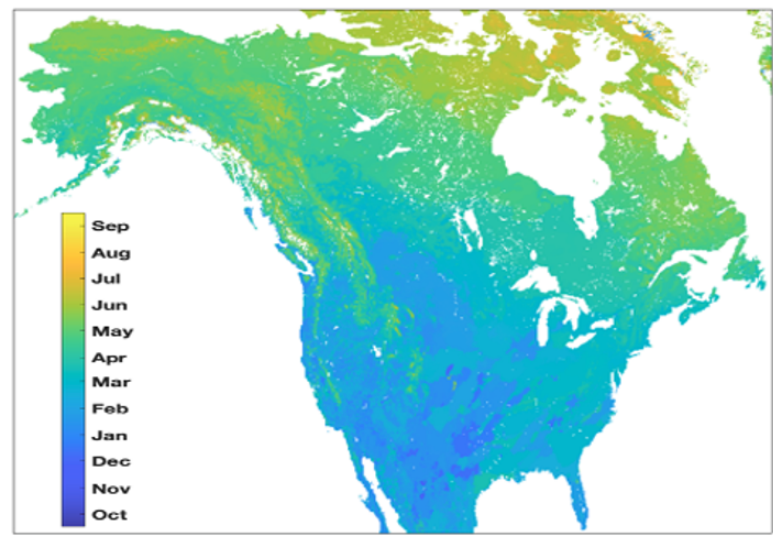

(b)

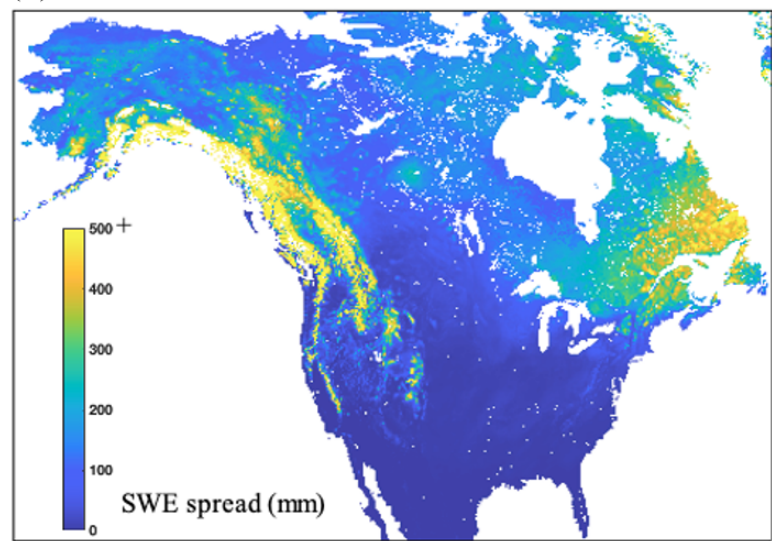

(d)

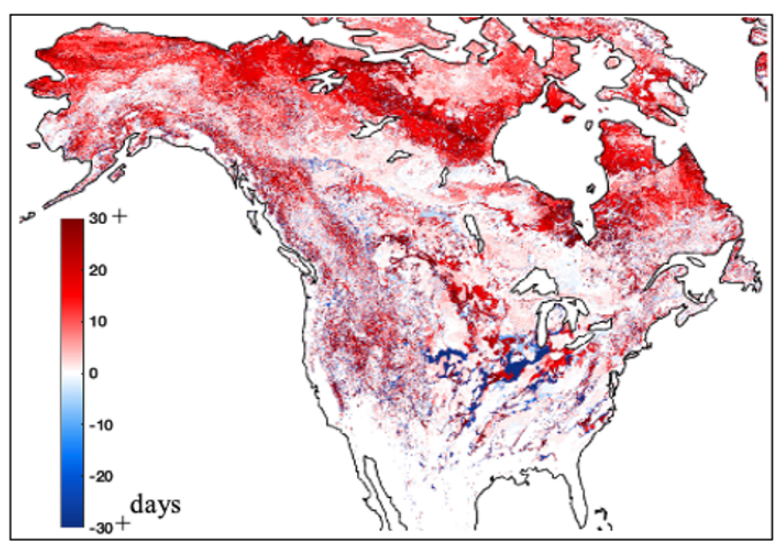

Figure 4. Spatial distributions of (a) the peak SWE amount, (b) the highest SWE spread amount, (c) the average day of year (DOY) with the highest ensemble SWE spread, and (d) the difference of average DOY between the highest ensemble SWE spread and the peak SWE (we are only showing/examining places where the DOY differences exist).

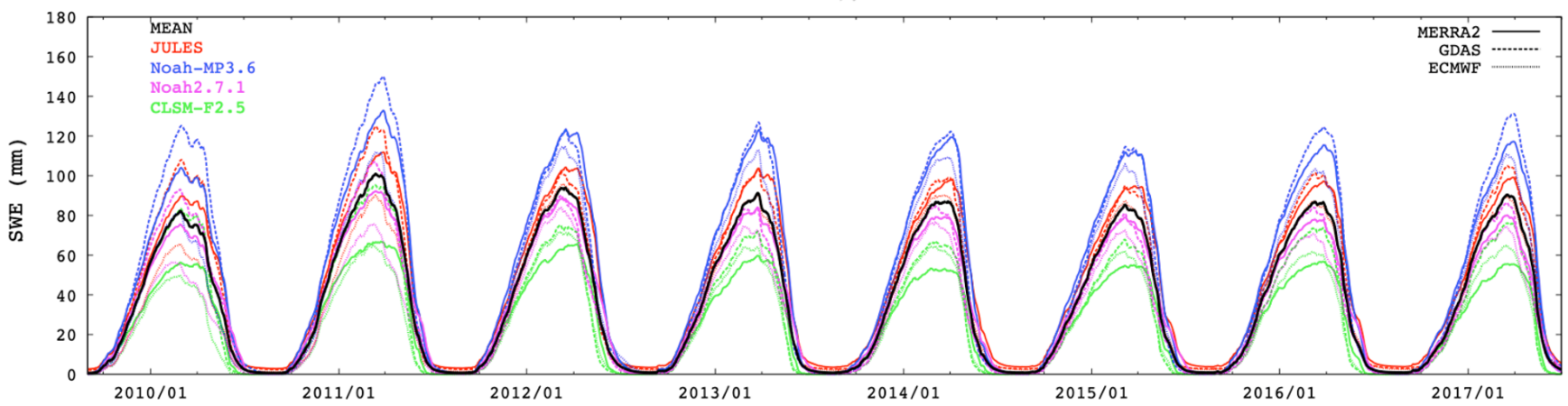

Figure 5. Time series of domain-averaged mean SWE. Different colors and line style were used to represent each ensemble; a bold black solid line represents the domain-averaged ensemble mean; the units are millimeters.

in global SWE and SWS estimation. For example, from Sect. 3.2.1 and 3.2.2, the usefulness of observations for reducing SWE uncertainty will be higher during the melt season in the high latitudes and western mountainous terrain, whereas having observations in the peak winter is generally more beneficial in the midlatitudes. Similarly, the timing of snow observations for collecting peak SWE changes with latitude. Finally, the results from Sect. 3.2.4 suggest that reliable SWE observations, rather than observations of boundary conditions (such as precipitation), may do more to mitigate the uncertainties in the current state of snow modeling. 


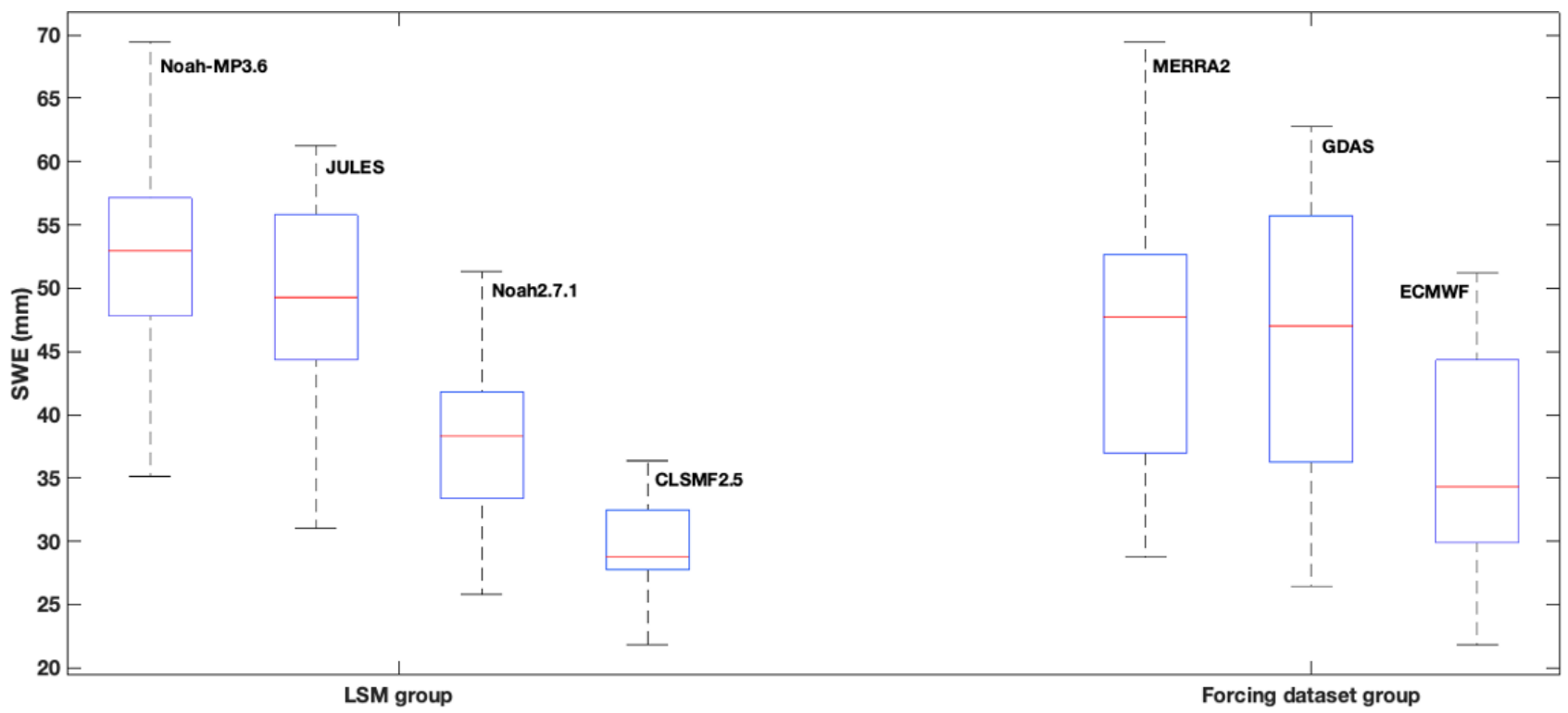

Figure 6. Distribution of North America mean annual average of SWE (i.e., interannual variability), grouped by the LSMs and forcing datasets (e.g., the box of Noah-MP3.6 represents the distribution of mean SWE, averaged from Noah-MP3.6 runs with all forcing datasets; the box of MERRA2 represents the distribution of mean SWE, averaged from all LSM runs with MERRA2 forcing data). For the LSM group, we used eight annual averages of SWE (from 2009 to 2017) for three different forcing datasets (a total of $8 \times 3$ ). For the forcing dataset group, eight annual averages of SWE for four different LSMs (total of $8 \times 4$ ) were used. The red line indicates SWE median; top and bottom of box are the 75th and 25th percentiles, and top and bottom of whiskers represent the maximum and minimum SWE with outliers (defined as more than 1.5 times the interquartile range, between $25 \%$ and $75 \%$ ) omitted.

\subsection{Uncertainty analysis for different land classifications}

In this section, we further explore the uncertainty in North American SWE estimates based on different land and snow classifications (described in Sect. 2.4.2).

\subsubsection{Uncertainty analysis on different topography}

We first evaluate the spatial variability of ensemble mean SWE within each mountain range. In Fig. 7a, box plots no. 12 and 13 represent the spatial variability of mean SWE for total mountain areas and non-mountain areas, respectively. Total mountain areas are computed by combining the 11 individual mountain domains, and all remaining areas are considered non-mountain areas. Across the entire continent, the mountain areas show higher spatial variability of SWE and higher median SWE than in non-mountain areas (median SWE: $50.17 \mathrm{~mm}$ vs. $23.03 \mathrm{~mm}, \sim 118 \%$ higher in mountain areas). Figure 7 a highlights the fact that SWE and its spatial variability differ from range to range. For example, most coastal mountain ranges (Coast, Alaska, and Torngat) have higher SWE with greater spatial variability than that of continental ranges (Appalachian, Brooks, Great Basin, Mackenzie, and US Rockies), excluding the Canadian Rockies. Comparisons of SWS in each mountain range (Fig. 7b) show that $\sim 50 \%$ of all mountain snow in North America is located in the Coast Mountains and the Canadian Rockies, which is consistent with the findings of Wrzesien et al. (2018).

The variability in the SEUP ensemble spread (i.e., among 12 ensemble members) of SWE and SWS across different mountain ranges is examined in Fig. $7 \mathrm{c}$ and d. Similar to the spatial variability in SWE (Fig. 7a), the Coast Mountains and Alaska Range have higher uncertainties in SWE among ensemble members, followed by the Cascades, Torngat, and the Canadian Rockies. Note that the second highest SWS uncertainty is found in the Canadian Rockies once integrated across the entirety of the mountain range.

To investigate the temporal variability of SWE over different mountain domains, we compared the mean seasonal cycle of SWE and SWS. Figure 8a and b show the time series of daily ensemble mean SWE and SWS for each mountain range, averaged for a water year. From both comparisons of SWE and SWS, it can be noted that there is significant variability in the timing of peak (and melt) SWE and SWS across the mountain ranges. The northern mountain ranges (e.g., Alaska, Brooks, Mackenzie, and Torngat) tend to have later dates of peak SWE and SWS, from early April to early May, while peak SWE in lower-latitude mountain ranges occurs between February and March. When exploring the time series of SWE and SWS for each ensemble, we find that JULES simulates non-seasonal snow in the Alaska Range and Coast Mountains (even after the glacier exclusions, not shown), while other LSMs do not. These different estima- 
(a)

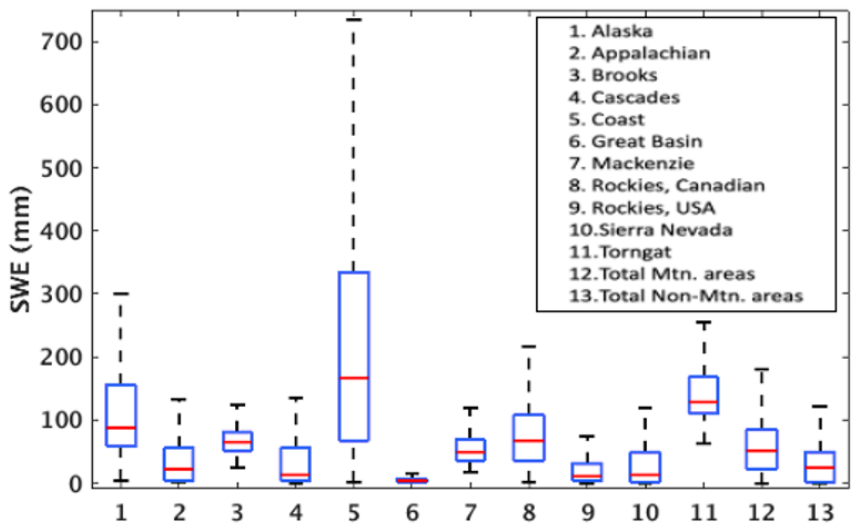

(c)

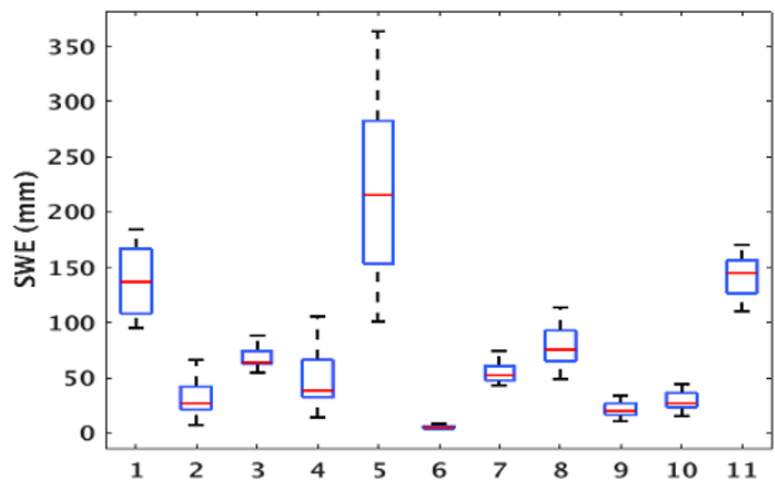

(b)

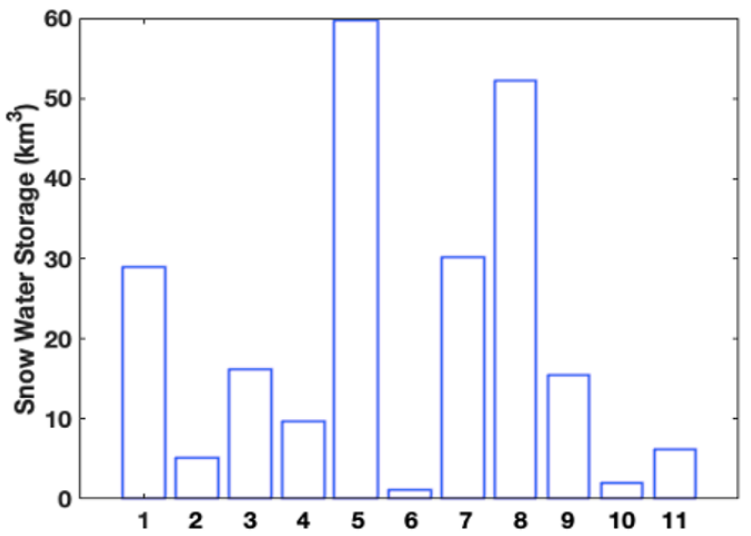

(d)

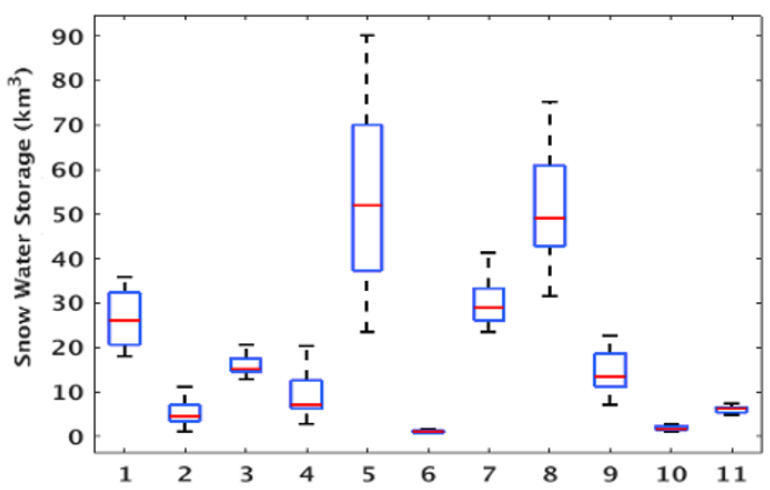

Figure 7. (a) Spatial variability of ensemble mean SWE (in millimeters) within each mountain range. Red line indicates SWE median; top and bottom of box are the 75th and 25th percentiles, and top and bottom of whiskers represent maximum and minimum SWE with outliers (defined as more than 1.5 times the interquartile range, between $25 \%$ and $75 \%$ ) omitted. (b) Total snow water storage (SWS; in cubic kilometers) within each mountain range, computed from the average of ensemble mean SWE over the entire time period. The spread of ensembles for (c) domain- and time-averaged SWE and (d) time-averaged SWS for the different mountain ranges.

tions are likely due to the different snow physics and parameterizations used in each LSM (see Table S1). The snow simulated in the summer season could explain the higher spread of SWE seen in the Alaska Range and the Coast Mountains.

Finally, we use the ensemble mean seasonal cycle of SWE and SWS to evaluate differences between mountain areas and non-mountain areas of North America. In Fig. 8c and d, we find that the daily mean SWE is greater in mountain areas than in non-mountain areas, while the total daily SWS is greater in non-mountain areas than mountain areas. This contrast is due to the significant difference in total area between the mountain regions and the non-mountain regions: nonmountainous areas cover approximately 5 times more space than mountainous areas. For total mountain areas, the maximum SWE is $202 \mathrm{~mm}$ and the maximum SWS is $616 \mathrm{~km}^{3}$. Alternatively, total non-mountain areas have $79 \mathrm{~mm}$ of maximum SWE and $988 \mathrm{~km}^{3}$ of maximum SWS; i.e., mountain areas have deeper snow, whereas more snow is stored in nonmountainous areas.
Compared with previous mountain snow studies over North America, the SEUP peak mountain SWS is 1.8 times the estimate of $342 \mathrm{~km}^{3}$ from the Canadian Sea Ice and Snow Evolution Network (CanSISE) data ensemble of Mudryk et al. (2015) and 0.6 times the estimate of $1006 \mathrm{~km}^{3}$ in Wrzesien et al. (2018). For non-mountain areas, the SEUP peak SWS is $\sim 1.5$ times the estimate of $678 \mathrm{~km}^{3}$ of the CanSISE data product. The estimated peak SWS over all of North America from SEUP is $1604 \mathrm{~km}^{3}$, which is $47.6 \%$ more than the previous CanSISE estimate $\left(1087 \mathrm{~km}^{3}\right)$ and $4.8 \%$ less than the Wrzesien et al. (2018) estimate $\left(1684 \mathrm{~km}^{3}\right)$. When compared with our simulation results, most strikingly, these studies find a lower estimation of SWS even in the nonmountain areas, though additional analysis is needed to determine if this is due to resolution differences or some other influence. The CanSISE SWE estimate is produced using a somewhat similar ensemble mean approach of SEUP, by combining observations and model estimates at $1^{\circ}$ spatial resolution. Therefore, the lower estimate of SWS in the CanSISE data product might be explained by their coarser spa- 
(a)

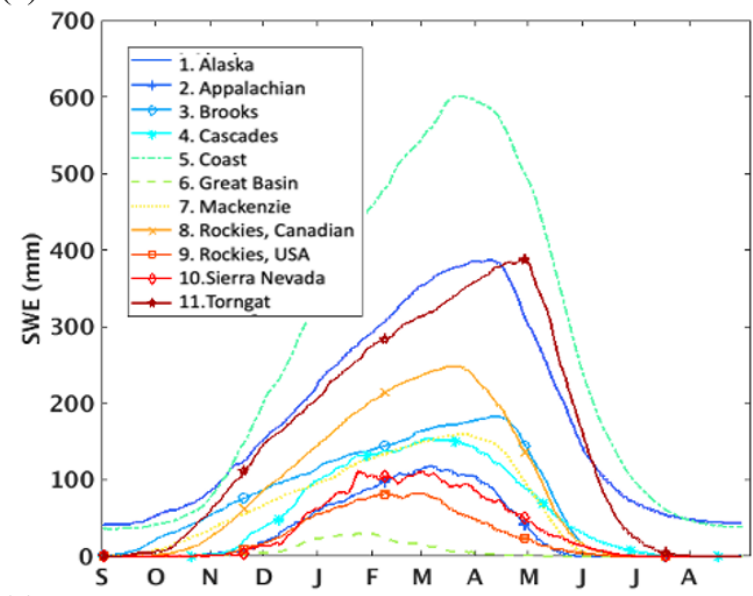

(c)

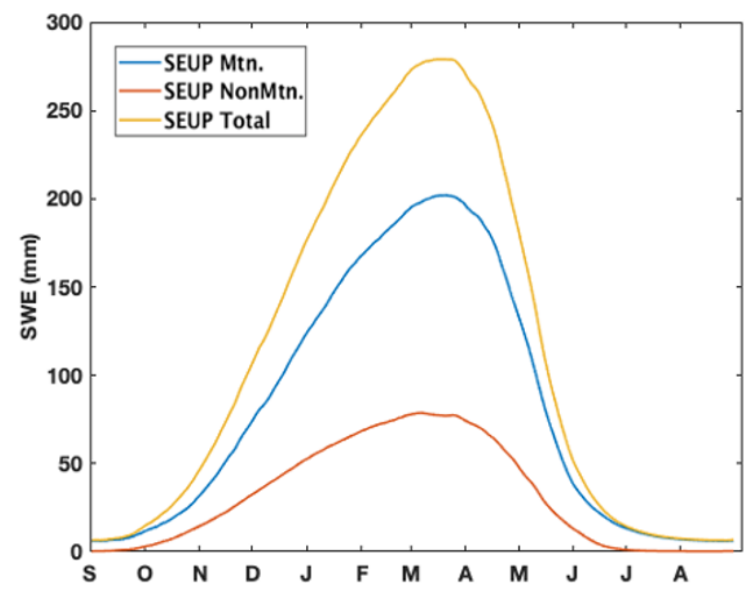

(b)

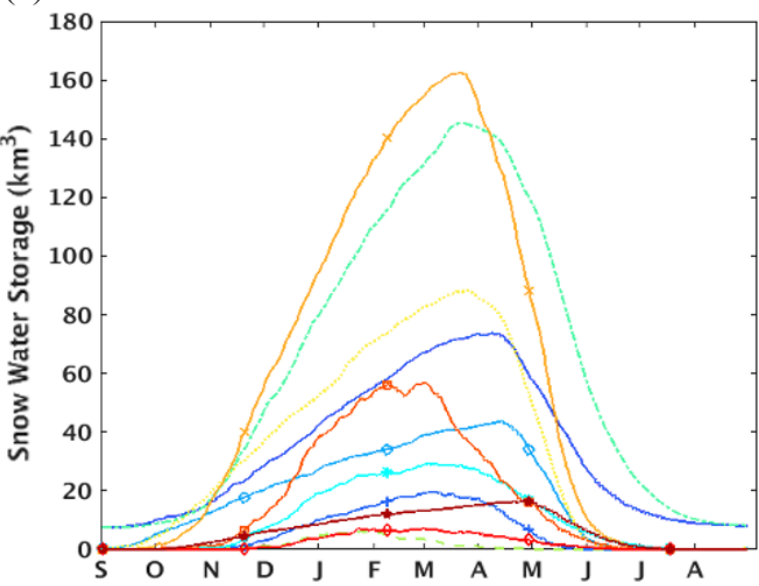

(d)

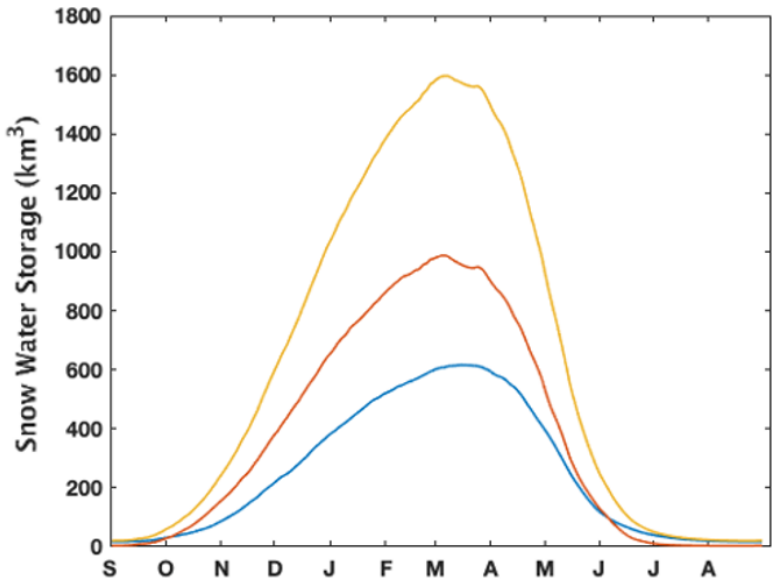

Figure 8. (a) Climatological SWE (in millimeters) within each mountain range, computed from domain ensemble mean SWE over a water year. (b) Total snow water storage (SWS; in cubic kilometers) climatology within each mountain range, computed from domain ensemble mean SWS over a water year. The mean seasonal cycle of domain-averaged SWE (c) and SWS (d) for mountain areas, non-mountain areas, and North America.

tial resolution compared to the simulation resolution of this study (i.e., at $5 \mathrm{~km}$ ). Studies such as Broxton et al. (2016) have highlighted the systematic underestimation of SWE from global reanalyses and continental-scale LDASs as a key issue. Previous studies also highlighted the limitations of coarse-resolution models, particularly in capturing snow accumulation in mountain areas, and suggested using a resolution of $<10 \mathrm{~km}$ (Ikeda et al., 2010; Kapnick and Delworth, 2013; Pavelsky et al., 2011; Wrzesien et al., 2017).

Despite similar identical total North American SWS estimation between SEUP and Wrzesien et al. (2018), there are significant differences in the partitioning between mountain and non-mountain SWS. SEUP estimates that $60 \%$ of all continental snow is located in non-mountains, while Wrzesien et al. (2018) gave an estimation of $60 \%$ of all continental snow in mountains. The CanSISE results suggested that $\sim 75 \%$ of all continental snow is located in non-mountains, though as noted above, CanSISE estimates may be under- estimated due to the coarse modeling resolution, especially in mountain areas. Since Wrzesien et al. (2018) used CanSISE for non-mountain SWS estimates, it is possible that their partitioning of mountain versus non-mountain snow is overestimated. In addition, while SEUP employs ensemble model simulations over an 8-year time period, Wrzesien et al. (2018) simulated the mountain snowpack using a single regional climate model (i.e., the Weather Research and Forecasting Model, WRF version 3.6, Skamarock et al., 2008; coupled to the Noah-MP3.6, Niu et al., 2011) forced by ERAInterim for a "representative year" (i.e., different single year for each mountain range). This proposed "representative climatology" was used at spatial resolutions of 27 and $9 \mathrm{~km}$ for the outer and inner domains, respectively. One possible reason for their higher SWS estimates in mountain areas ( $\sim 63 \%$ greater than SEUP) is that their representative year had more snow compared with our average climatology approach over the entire study period, which included low snow 
(drought) years. Another reason why Wrzesien et al. (2018) had more snow in the mountain is because they used a highresolution $(9 \mathrm{~km})$ atmospheric model. The coarser-resolution atmospheric models generally do not simulate enough snowfall in the mountains due to their inability to resolve the complexity of the topography (Lundquist et al., 2019). The use of a different glacier mask is another possible explanation for this discrepancy. Note that any change in total water storage from GRACE data is not solely due to snow accumulation or melt. We also compare the variability of SWS among different LSM simulations (not shown) and find that the highest mountain SWS $\left(812 \mathrm{~km}^{3}\right)$ was estimated from Noah-MP3.6 simulations while Wrzesien et al. (2018) showed the SWS estimate of $1006 \mathrm{~km}^{3}$ from their simulation of WRF 3.6 using Noah-MP. Note that the Noah-MP3.6 is the most recent and advanced model among SEUP LSMs and has been shown to perform better in previous studies (e.g., Wrzesien et al., 2015).

Overall, the analysis of SWE uncertainty over different topographical regimes confirms that mountain ranges have greater SWE variability among ensemble members than nonmountain regions, likely due to the methods used by the models to resolve the complex and spatially variable processes over such terrain and the ability of forcing data to capture orographic effects. These limitations should be addressed through further evaluation of the differences and capabilities of LSMs to simulate mountain snow and may also benefit from observational data at a high spatio-temporal resolution over such areas. Further, as noted above, there are still significant disagreements in the current understanding of the basic partition of SWE and SWS between mountainous and nonmountainous regions, caused by a variety of factors which are not easy to resolve.

\subsubsection{Uncertainty analysis stratified by snow classes}

The distribution of ensemble mean SWE and SWS (Fig. 9a and b) was computed over the entire time period using the snow class definitions that are shown in Fig. 1. Across the entire continent, the Ice region shows the highest estimate of SWE with the highest spatial variability, followed by Tundra, Taiga, Maritime, Warm Forest, Prairie, and Ephemeral regions. Higher latitudes tend to have higher estimates of SWE and greater spatial variability. Non-seasonal snow was estimated in the Ice region, even though glaciers were excluded, which may explain the highest SWE and its variability (as discussed earlier in Sect. 3.3.1). However, the SWS in the Ice regions makes up less than $2.6 \%$ of the total over North America. Most strikingly, we find that more than $50 \%$ of all continental snow is located in the Tundra region (SWS: $281 \mathrm{~km}^{3}$ with median SWE: $54 \mathrm{~mm}$ ).

To evaluate SWE uncertainty by different snow regimes, we compare the ensemble spread of mean SWE and SWS for each snow class. Figure $9 \mathrm{c}$ and d show the spread of mean SWE and SWS for all 12 ensemble members as a function of different snow classes. Both our spatial variability analysis and uncertainty analysis among ensemble members of SWE and SWS estimates provide new insights on the relative importance of different snow classes; the Tundra region has the greatest total SWS and large ensemble spread in those estimates between models; Taiga and Maritime regions also have a significant fraction of the total North American SWS and show high variability in SWE estimates likely due to LSM handling of vegetation impacts, such as canopy interception and sublimation. The SEUP results indicate that SWE estimates in the Tundra region are more consistent between ensemble members, likely because the vegetation is sparse there; however, given the large areal extent, accurate SWE estimates are especially critical in estimating total SWS in the Tundra region. Further, we note that the Tundra region is subject to snow erosion and sublimation losses, two processes that the LSMs used in this study do not explicitly simulate. These results point to the need for high accuracy in shallow snow observations that cover large regions, such as Tundra or Prairie, while high spatial resolution in these areas may be less important; the high resolution of SWE observation is more suitable for vegetated areas such as Taiga and Maritime.

\subsubsection{Influence of vegetation on SWE uncertainty}

An assessment of snow estimation uncertainty as a function of vegetation is presented in this section. Here we focus primarily on the differences in snow simulations over forested and non-forested areas, since forest snow processes are a model feature that is handled differently between models (Rutter et al., 2009). The forest category includes the evergreen forest, deciduous forest, and mixed forest land cover classes, whereas the non-forest category captures the rest of the land cover categories of Fig. 1d. The spatial variations in ensemble mean SWE as well as the ensemble mean SWS for forested and non-forested areas are shown in Fig. 10a and $\mathrm{b}$, respectively. Figure 10a indicates that the non-forested regions have larger spatial variability than the forested areas. The larger spatial variability in SWE over the non-forested regions is likely explained by the differences in the areal coverage of forests and non-forests (Fig. 1d). The bar plot in Fig. 10b shows that $66 \%$ of snow in North America is located in the non-forested regions.

Figure 10c and d show the uncertainty in SWE and SWS among the 12 ensembles for forests and non-forests. For both SWE and SWS, the higher spread is seen in the forested regions. This finding is consistent with previous studies that showed the larger spread of snow estimates from model simulations in forested regions (Chen et al., 2014; Essery et al., 2009; Feng et al., 2008; Kim et al., 2019; Rutter et al., 2009). Therefore, these results indicate that future observational efforts should, in part, focus on forested areas and further highlight the need for better understanding the effect of forests on snow simulations. 
(a)

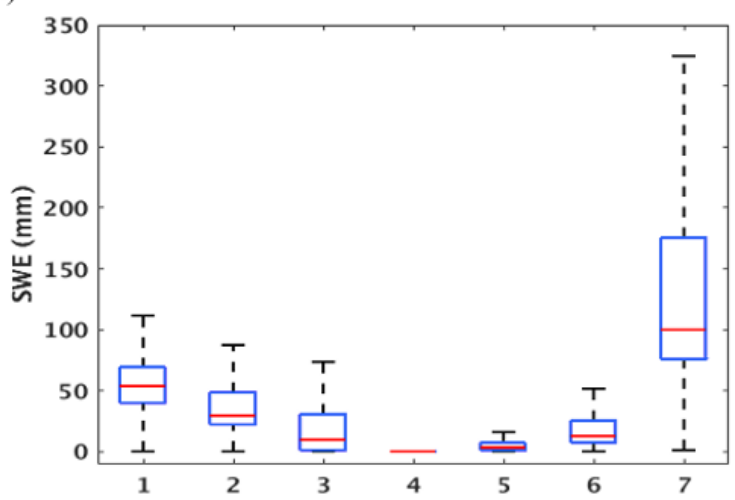

(c)

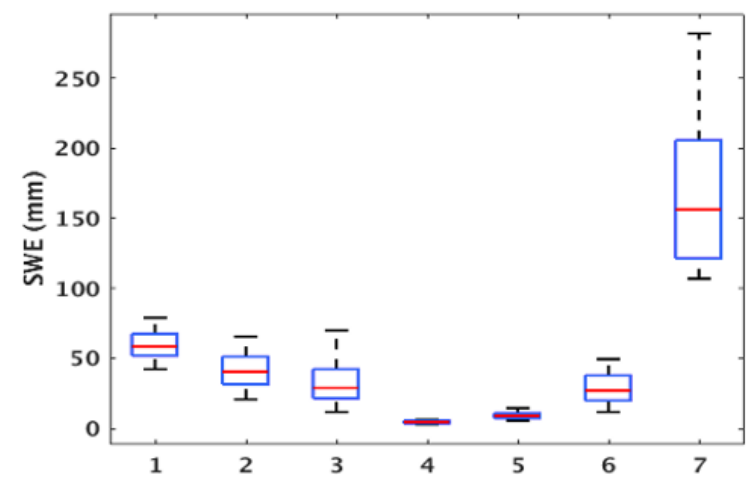

(b)

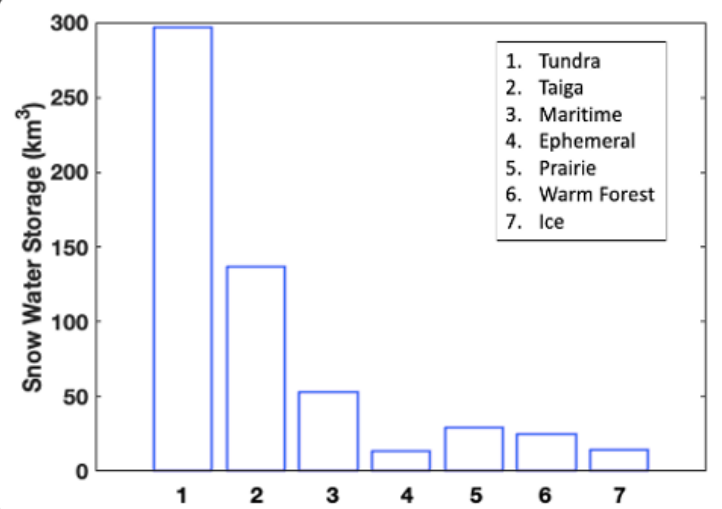

(d)

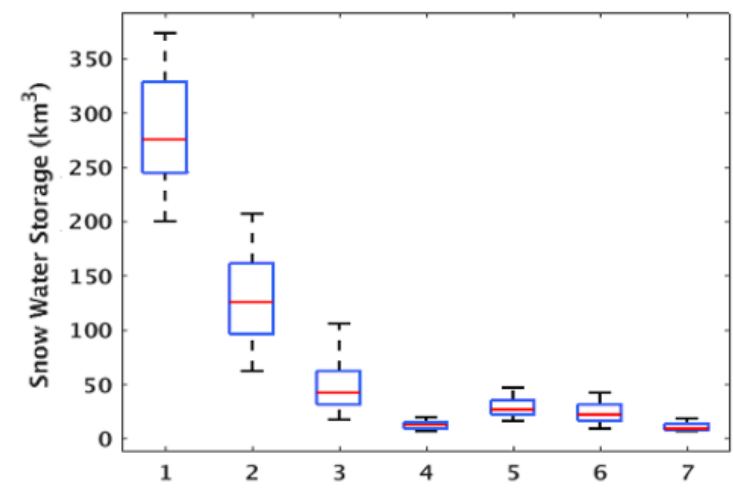

Figure 9. Same as Fig. 7 but for each snow class.

\subsection{Uncertainties in the runoff estimation}

Since runoff $(R)$ estimation, in particular, is significantly influenced by snow evolution, here we examine the impact of uncertainty in SWE estimation on the $R$ estimates and their uncertainty across North America. Similar to Fig. 4, seasonality of $R$ estimates and their uncertainty are evaluated during each winter season and over the entire time period and quantified by computing the average DOY with the highest ensemble spread and peak $R$. Figure 11 shows the average DOY with the highest spread in order to identify the (a) times of high uncertainty in $R$, (b) average DOY with the peak $R$, (c) highest $R$ ensemble spread, and (d) magnitude of the peak $R$. Variability in the date of the peak $R$ uncertainty and peak $R$ ranges from June-August in the high latitudes, whereas at lower latitudes the dates can be outside this range. Similar to the patterns in Fig. $4 \mathrm{c}$ and d, the largest spread and peak $R$ amounts are seen along the northern Pacific coastline and in eastern Canada along the northern Atlantic coastline (excluding the mid-Atlantic and southeastern United States). Figure $11 \mathrm{a}$ and $\mathrm{b}$ indicate that the seasonality in the highest $R$ spread and highest $R$ values is generally matched. In other words, the largest uncertainty in $R$ occurs at the same time as the peak $R$, which is different from the patterns shown in Fig. 4 where the largest SWE uncertainty is generally during the melt season after peak SWE was achieved.
Overall, both Figs. 4 and 11 show the strong influence of SWE on $R$ over most of North America and, in particular, during the snowmelt season. In order to further examine this, we explore the difference between average DOY of peak SWE and its spread and average DOY of peak $R$ and its spread. Figure 11e shows this date difference of average DOY of highest uncertainty (DOY of peak spread in $R$ minus the DOY of peak spread in SWE) and provides a measure of the spatio-temporal dependence of SWE uncertainty to $R$ uncertainty. Figure 11f shows the date difference between the average DOY of highest SWE and highest $R$, which provides a measure of temporal dependence of highest SWE on the highest $R$. If this difference is negative, it likely indicates that SWE is not a primary driver of runoff. On the other hand, if this difference is positive, it suggests that SWE has an influence on the runoff regime. The magnitude of this (positive) difference also provides a measure of the timescale over which they are correlated.

We find, from both Fig. 11e and $\mathrm{f}$, that the times of peak $R$ and uncertainty in peak $R$ occur later in the year than those of peak SWE and uncertainty in peak SWE over most of the domain. Further, the places where we have the negative values in both figures are the locations dominated by nonsnow $R$ in the lower latitudes. Over the Tundra and Taiga regions, the difference in the average DOY regimes of SWE 
(a)

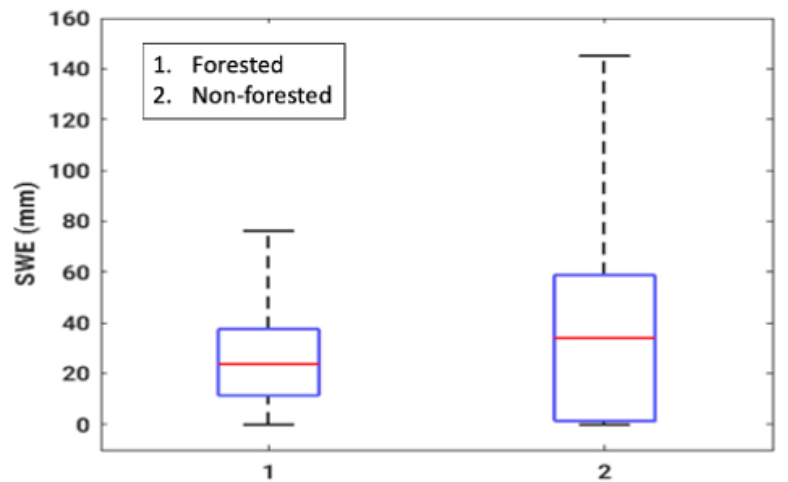

(c)

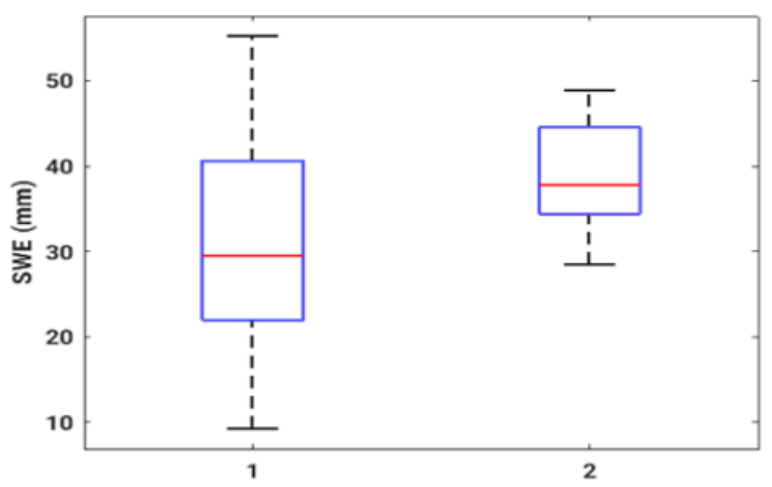

(b)

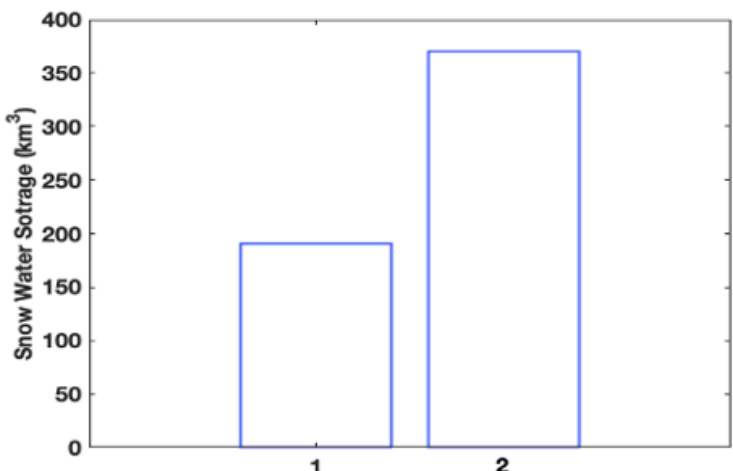

(d)

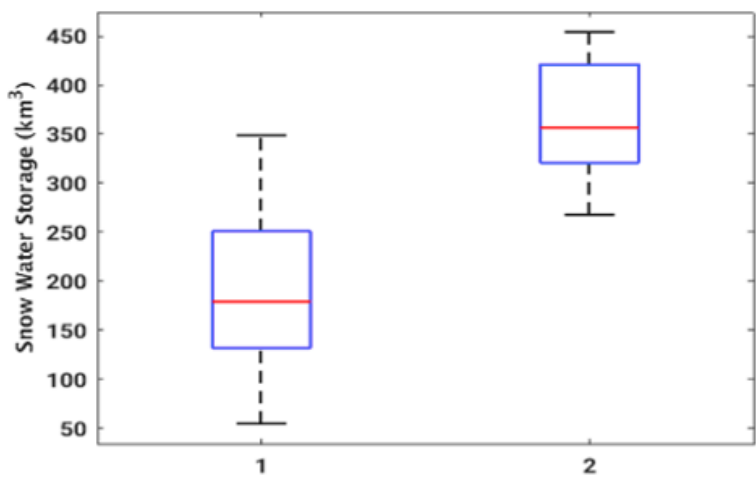

Figure 10. Same as Fig. 7 but for forested areas vs. non-forested areas.

and $R$ is about $20-40 \mathrm{~d}$, whereas this lag increases to more than 2 months over the Prairie regions. Over the mountainous terrain, $R$ uncertainty is more closely tied with the SWE uncertainty $(\sim 20 \mathrm{~d})$.

This analysis reconfirms that there is generally explicit snow runoff signal during the melt season, and increased uncertainty in $R$ appears related to uncertainty in preceding SWE estimates. Figure 11e and f also provide a measure of the spatio-temporal utility of SWE measurements when considering the objective of improving $R$ estimation. For example, these figures suggest that SWE estimates approximately $60-80 \mathrm{~d}$ prior to the peak flow are likely to provide the most utility to $R$ estimation over the Prairie regions. Since the DOY differences are smaller over the Tundra region, the optimal times for SWE measurements $(20 \mathrm{~d}$ prior to the peak flow) are less offset relative to the time of peak $R$. While this is a preliminary analysis that requires further exploration, it helps to provide insight into the need for improved snow data to improve streamflow estimation. A more detailed examination of the influence of SWE-runoff uncertainties, an investigation into the utility of SWE observations to reduce SWE uncertainty, and thereby runoff uncertainty are left for future work.

\section{Summary and conclusions}

This study employs an ensemble modeling approach to quantify the spatial and temporal uncertainties in SWE over North America, as estimated by operational LSMs and forcing data. Specifically, the study quantifies how uncertainty in SWE varies with key land surface characteristics such as topography, vegetation, and snow climate and evaluates the spatiotemporal influence of significant SWE uncertainty on runoff estimation. A primary goal of this study is to establish a baseline assessment of current global- or continental-scale operational capabilities and identify potential opportunities where improvements or SWE observations could inform both science and application needs.

The SEUP simulated snow estimates are compared against a number of spatially distributed reference snow products, which show a good match over the majority of the modeling domain, with an underestimation over the mountainous regions. The evaluation metrics provide confirmation that the SEUP ensemble provides a reasonable representation of the snow uncertainty in macroscale snow modeling. Over the entire North American domain, the analysis of the SEUP ensemble indicates that the uncertainty in SWE within this ensemble is driven more by the LSM differences than the choice of forcing data. This suggests that improvements in 
(a)

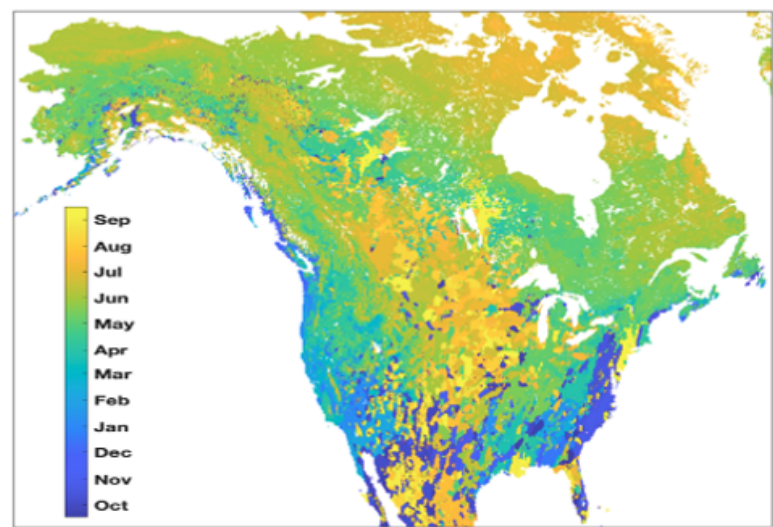

(c)

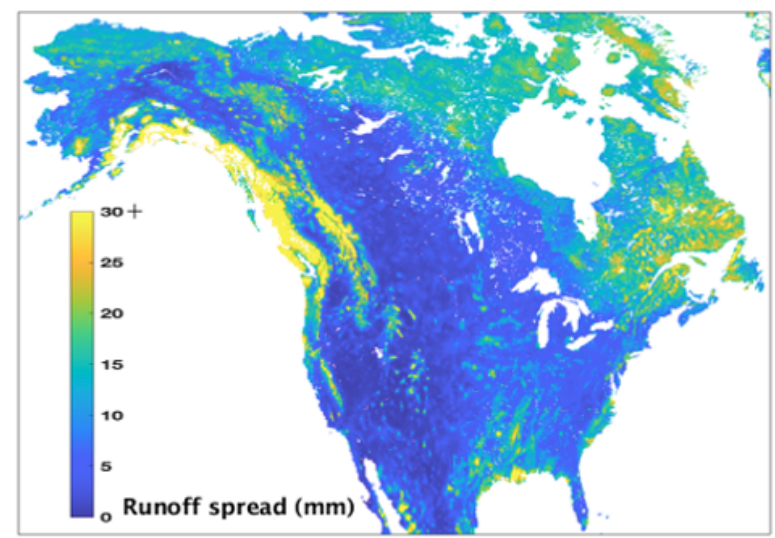

(e)

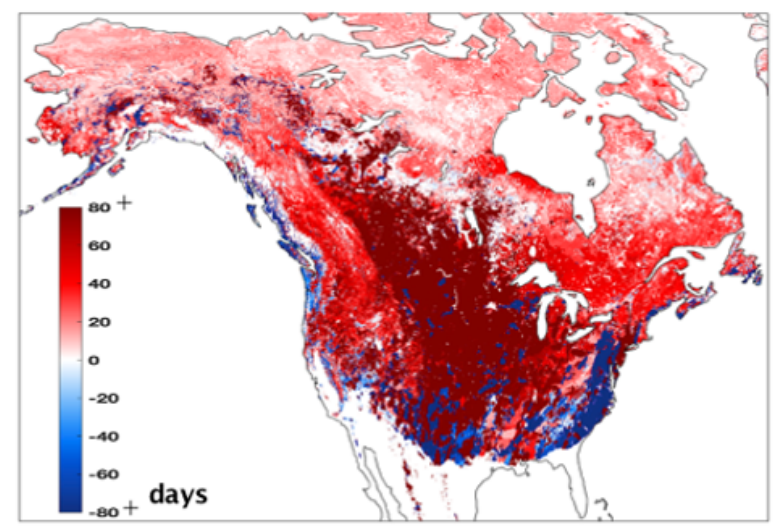

(b)

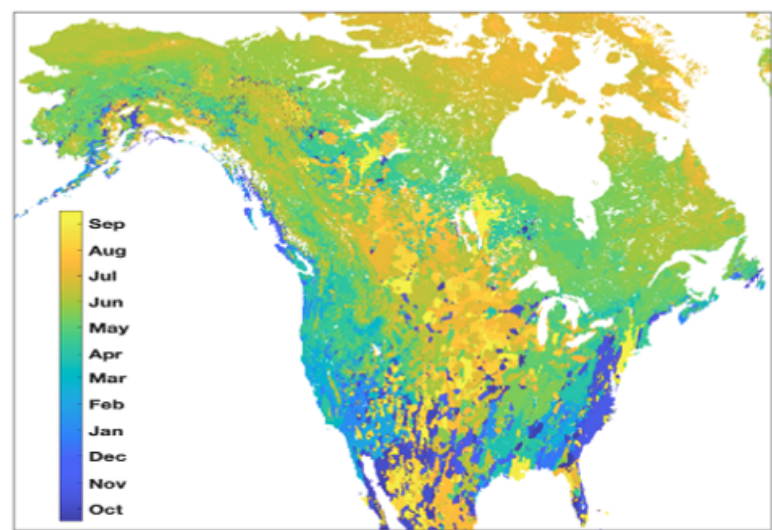

(d)

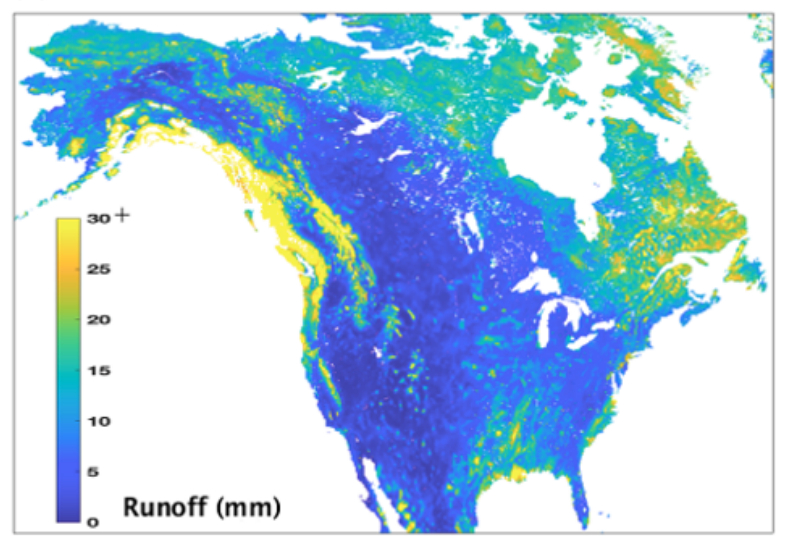

(f)

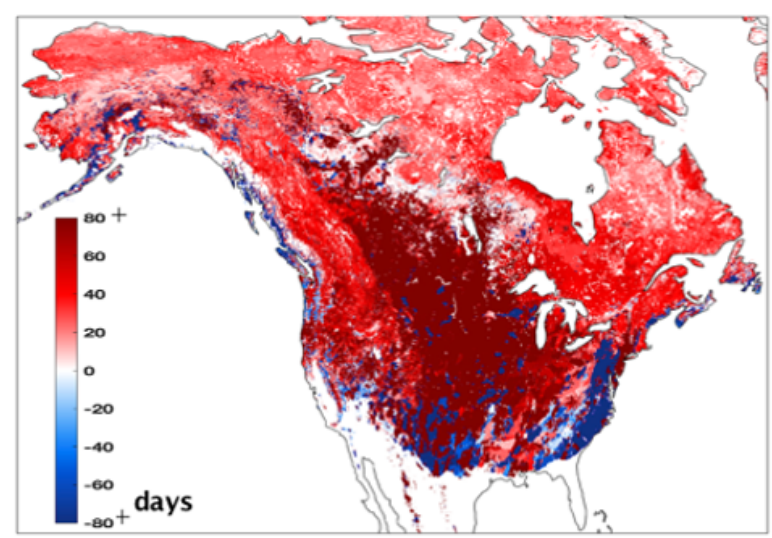

Figure 11. Spatial distributions of (a) the average day of year (DOY) with the highest ensemble $R$ spread, (b) the average DOY with the peak $R$, (c) the highest $R$ spread amount, (d) the peak $R$ amount, (e) the difference of average DOY between the highest $R$ spread and the highest SWE spread, and (f) the difference of average DOY between the peak $R$ and the peak SWE.

model physics or increased observations of SWE (ground or remote sensing) rather than improvement in meteorological boundary conditions at this macroscale are likely to provide more benefit in reducing snow assessment uncertainty. Though given the underestimation of SWE in mountains by all ensemble members, and high SWE uncertainty found in areas with the deepest snow, particularly the Pacific coast- line, higher-resolution atmospheric models may be needed to resolve topography and orographic effects in these regions.

Our analysis indicates that there is substantial uncertainty, both SWE and SWS, within forested regions. The Taiga and Maritime regions have a significant fraction of the total North American SWS while also exhibiting high variability in SWE estimation due to the influence of vegetation. The high spread 
in SWE and SWS seen over the forested areas suggests the need for improved measurements and modeling of snow in these areas. While these results suggest the need for additional observational constraints to reduce the uncertainty within the models, deep snow and forests also present difficult challenges for remote sensing. These areas continue to be the greatest gaps for global SWE estimation.

The greatest SWS uncertainty is seen in the nonmountainous areas. There are disagreements in the existing literature as to the relative attribution of snow storage over the mountainous and non-mountainous regions in North America. Though the mountain SWS estimates from SEUP are similar to those generated in prior studies, we conclude that the current partitioning of SWE and SWS between mountainous and non-mountainous areas merits further investigation. Our results provide new insights on the relative importance of the Tundra snow regions where the greatest total SWS is found and where snowmelt can have important implications on permafrost, arctic ecosystems, and global circulation models. Accurate SWE estimates in shallow snow environments (i.e., Tundra and Prairie) are critical to developing an accurate estimate of global snow partitioning and reducing SWS uncertainty over these regions.

There is significant variability in the seasonality of SWE uncertainty and the uncertainty in peak SWE. At midlatitudes, the average DOY containing peak SWE and the largest SWE uncertainty occurs in the December-April time frame. At high latitudes, particularly in Tundra and Taiga regions, the uncertainty in SWE is largest during May-June, after the peak SWE. These results suggest that SWE measurements collected during the melt season are likely to provide more benefit in reducing SWE uncertainty at high latitudes and in some western mountainous terrain, whereas observations at (or near) peak SWE accumulation are valuable over the midlatitudes.

This study also examines the influence of SWE on runoff. The first-order control of SWE on snowmelt runoff over most of North America is highlighted in this study, which points to the importance of improved SWE estimates to inform water supply and management applications. Overall, this study provides a valuable benchmark on the uncertainties in macroscale snow modeling, which can serve as a guide for prioritizing model improvement needs and developing observational requirements. We acknowledge that the influence of the sources of uncertainty such as the choice of model parameters and spatial resolution of topographic features are not examined in this study. Additional work is needed to understand the specific drivers of uncertainty within the model physics, better characterize the snow storage over the mountain and non-mountainous regions, and quantify the regional influence of SWE uncertainty on water availability. More detailed requirements of snow observations (e.g., choice of observation types and sampling methods) will be focused on in future efforts by conducting observing system simulation experiments (OSSEs) that systematically quantify the worth of the existing data and data yet to be collected. The results from this future effort are expected to help in the choice and refinement of sensors for the accurate characterization of global, terrestrial snow mass.

Code and data availability. The Modern-Era Retrospective Analysis for Research and Applications, version 2 (MERRA2; Gelaro et al., 2017; Molod et al., 2015), the meteorological dataset used in this study is distributed by the NASA Goddard Global Modeling and Assimilation Office (GMAO, https://gmao.gsfc.nasa.gov/ reanalysis/MERRA-2/data_access/; Gelaro et al., 2017). The operational Global Data Assimilation System (GDAS; Derber et al., 1991) data are publicly available from the US National Centers for Environmental Prediction (NCEP) at https://nomads.ncep. noaa.gov/pub/data/nccf/com/gfs/prod. The European Centre for Medium-Range Weather Forecasts (ECMWF; Molteni et al., 1996) data used in this study are not publicly available and are made available under license (https://www.ecmwf.int/en/forecasts/datasets). The Snow Data Assimilation System (SNODAS; Barrett, 2003) data products, the daily gridded estimates of snow depth and SWE developed by the University of Arizona (UA; Zeng et al., 2018), and the daily, gridded snow depth analysis from the Canadian Meteorological Centre (CMC; https://doi.org/10.5067/W9FOYWH0EQZ3, Brown and Brasnett, 2010) are available on the National Snow and Ice Data Center's (NSIDC) data site (https://nsidc.org/data, last access: 5 February 2021).

Supplement. The supplement related to this article is available online at: https://doi.org/10.5194/tc-15-771-2021-supplement.

Author contributions. RSK, SK, CV, PH, JL, and MD conceptualized and initiated this work. RSK conducted the model runs. RSK, $\mathrm{SK}$, and CV designed and performed the ensemble evaluation and uncertainty analysis and drafted the manuscript. PH, JL, LM, MD, AB, EJK, BAF, EDG, MLW, CG, MS, HPM, NC, JMP, JJ, and YC helped to perform the analysis and write and revise the manuscript. DM and SW provided guidance on using the NASA LIS. All authors reviewed the paper with thorough discussion before submission.

Competing interests. The authors declare that they have no conflict of interest.

Acknowledgements. Funding for this work was provided by the NASA Terrestrial Hydrology Program (NNH16ZDA001N). Computing was supported by the resources at the NASA Center for Climate Simulation. NCAR is supported by the National Science Foundation under cooperative agreement no. 1852977. Additional support was provided by the US Bureau of Reclamation under cooperative agreement grant number R11AC80816 as well as the NASA Advanced Information System Technology Program (80NSSC17K0254). 
Financial support. This research has been supported by the National Aeronautics and Space Administration (grant nos. NNH16ZDA001N and 80NSSC17K0254) and the US Bureau of Reclamation (grant no. R11AC80816).

Review statement. This paper was edited by Jürg Schweizer and reviewed by Richard L. H. Essery, J. Ignacio López-Moreno, and one anonymous referee.

\section{References}

Barnett, T. P., Adam, J. C., and Lettenmaier, D. P.: Potential impacts of a warming climate on water availability in snow-dominated regions, Nature, 438, 303-309, https://doi.org/10.1038/nature04141, 2005.

Barrett, A. P.: National operational hydrologic remote sensing center snow data assimilation system (SNODAS) products at NSIDC, National Snow and Ice Data Center, Cooperative Institute for Research in Environmental Sciences, Boulder, CO, USA, p. 19, 2003.

Berghuijs, W. R., Woods, R. A., and Hrachowitz, M.: A precipitation shift from snow towards rain leads to a decrease in streamflow, Nat. Clim. Change, 4, 583-586, https://doi.org/10.1038/nclimate2246, 2014.

Berghuijs, W. R., Woods, R. A., Hutton, C. J., and Sivapalan, M.: Dominant flood generating mechanisms across the United States, Geophys. Res. Lett., 43, 4382-4390, https://doi.org/10.1002/2016GL068070, 2016.

Best, M. J., Pryor, M., Clark, D. B., Rooney, G. G., Essery, R. L. H., Ménard, C. B., Edwards, J. M., Hendry, M. A., Porson, A., Gedney, N., Mercado, L. M., Sitch, S., Blyth, E., Boucher, O., Cox, P. M., Grimmond, C. S. B., and Harding, R. J.: The Joint UK Land Environment Simulator (JULES), model description Part 1: Energy and water fluxes, Geosci. Model Dev., 4, 677-699, https://doi.org/10.5194/gmd-4-677-2011, 2011.

Blyth, E., Best, M., Cox, P., Essery, R., Boucher, O., Harding, R., Prentice, C., Vidale, P. L., and Woodward, I.: JULES: a new community land surface model, IGBP Newsl., 66, 9-11, 2006.

Bohn, T. J., Sonessa, M. Y., and Lettenmaier, D. P.: Seasonal Hydrologic Forecasting: Do multimodel ensemble averages always yield improvements in forecast skill?, J. Hydrometeorol., 11, 1358-1372, https://doi.org/10.1175/2010JHM1267.1, 2010.

Brooks, P. D., Grogan, P., Templer, P. H., Groffman, P., Öquist, M. G., and Schimel, J.: Carbon and nitrogen cycling in snow-covered environments, Geography Compass, 5, 682-699, https://doi.org/10.1111/j.1749-8198.2011.00420.x, 2011.

Brown, R., Tapsoba, D., and Derksen, C.: Evaluation of snow water equivalent datasets over the Saint-Maurice river basin region of southern Québec, Hydrol. Process., 32, 2748-2764, 2018.

Brown, R. D. and Brasnett, B.: Canadian Meteorological Centre (CMC) daily snow depth analysis data, version 1, National Snow and Ice Data Center, https://doi.org/10.5067/W9FOYWH0EQZ3, 2010.

Broxton, P. D., Zeng, X., and Dawson, N.: Why do global reanalyses and land data assimilation products underestimate snow water equivalent?, J. Hydrometeorol., 17, 2743-2761, https://doi.org/10.1175/JHM-D-16-0056.1, 2016.
Chen, F., Barlage, M., Tewari, M., Rasmussen, R., Jin, J., Lettenmaier, D., Livneh, B., Lin, C., Miguez-Macho, G., Niu, G. Y., Wen, L., and Yang, Z. L.: Modeling seasonal snowpack evolution in the complex terrain and forested colorado headwaters region: A model intercomparison study, J. Geophys. Res., 119, 13-795, https://doi.org/10.1002/2014JD022167, 2014.

Clark, M. P., Hendrikx, J., Slater, A. G., Kavetski, D., Anderson, B., Cullen, N. J., Kerr, T., Örn Hreinsson, E., and Woods, R. A.: Representing spatial variability of snow water equivalent in hydrologic and land-surface models: A review, Water Resour. Res., 47, 435, https://doi.org/10.1029/2011WR010745, 2011.

Cosgrove, B. A., Lohmann, D., Mitchell, K. E., Houser, P. R., Wood, E. F., Schaake, J. C., Robock, A., Marshall, C., Sheffield, J., Duan, Q., Luo, L., Higgins, R. W., Pinker, R. T., Tarpley, J. D., and Meng, J.: Real-time and retrospective forcing in the North American Land Data Assimilation System (NLDAS) project, J. Geophys. Res.-Atmos., 108, 8842, https://doi.org/10.1029/2002JD003118, 2003.

Dawson, N., Broxton, P., Zeng, X., Leuthold, M., Barlage, M., and Holbrook, P.: An evaluation of snow initializations in ncep global and regional forecasting models, J. Hydrometeorol., 17, 18851901, https://doi.org/10.1175/JHM-D-15-0227.1, 2016.

Derber, J. C., Parrish, D. F., and Lord, S. J.: The new global operational analysis system at the national-meteorological-center, Weather Forecast., 6, 538-547, https://doi.org/10.1175/15200434(1991)006<0538:tngoas>2.0.co;2, 1991 (data available at: https://nomads.ncep.noaa.gov/pub/data/nccf/com/gfs/prod, last access: 11 February 2021).

Dietz, A. J., Kuenzer, C., Gessner, U., and Dech, S.: Remote sensing of snow - a review of available methods, Int. J. Remote Sens., 33, 4094-4134, https://doi.org/10.1080/01431161.2011.640964, 2012.

Dirmeyer, P. A., Gao, X., Zhao, M., Guo, Z., Oki, T., and Hanasaki, N.: GSWP-2: multimodel analysis and implications for our perception of the land surface, B. Am. Meteorol. Soc., 87, 13811398, https://doi.org/10.1175/BAMS-87-10-1381, 2006.

Dozier, J., Bair, E. H., and Davis, R. E.: Estimating the spatial distribution of snow water equivalent in the world's mountains, WIRES Water, 3, 461-474, https://doi.org/10.1002/wat2.1140, 2016.

Ducharne, A., Koster, R. D., Suarez, M. J., Stieglitz, M., and Kumar, P.: A catchment-based approach to modeling land surface processes in a general circulation model: 2. Parameter estimation and model demonstration, J. Geophys. Res.-Atmos., 105, 24823 24838, https://doi.org/10.1029/2000JD900328, 2000.

Durand, M., Gatebe, C., Kim, E., Molotch, N., Painter, T. H., Raleigh, M., Sandells, M., and Vuyovichi C.: Assessing Approaches for Measuring Water in Earth's Seasonal Snow, available at: https://goo.gl/sFkxHc (last access: 5 February 2021), 2019.

Dutra, E., Kotlarski, S., Viterbo, P., Balsamo, G., Miranda, P. M. A., Schär, C., Bissolli, P., and Jonas, T.: Snow cover sensitivity to horizontal resolution, parameterizations, and atmospheric forcing in a land surface model, J. Geophys. Res.-Atmos., 116, D21109, https://doi.org/10.1029/2011JD016061, 2011.

Ek, M. B., Mitchell, K., and Lin, Y.: Implementation of Noah land surface model advances in the National Centers for Environmental Prediction operational mesoscale Eta model, J. Geophys. Res., 108, 8851, https://doi.org/10.1029/2002JD003296, 2003. 
Essery, R., Rutter, N., Pomeroy, J., Baxter, R., Stahli, M., Gustafsson, D., Barr, A., Bartlett, P., and Elder, K.: SnowMIP2: An evalution of forest snow process simulation, B. Am. Meteorol. Soc., 90, 1120-1136, https://doi.org/10.1175/2009BAMS2629.1, 2009.

Feng, X., Sahoo, A., Arsenault, K., Houser, P., Luo, Y., and Troy, T. J.: The impact of snow model complexity at three CLPX sites, J. Hydrometeorol., 9, 1464-1481, https://doi.org/10.1175/2008JHM860.1, 2008.

Fick, S. E. and Hijmans, R. J.: WorldClim 2: new 1-km spatial resolution climate surfaces for global land areas, Int. J. Climatol., 37, 4302-4315, https://doi.org/10.1002/joc.5086, 2017.

Forman, B. A., Reichle, R. H., and Rodell, M.: Assimilation of terrestrial water storage from GRACE in a snow-dominated basin, Water Resour. Res., 48, W01507, https://doi.org/10.1029/2011WR011239, 2012.

Foster, J. L., Hall, D. K., Eylander, J. B., Riggs, G. A., Nghiem, S. V., Tedesco, M., Kim, E., Montesano, P. M., Kelly, R. E. J., Casey, K. A., and Choudhury, B.: A blended global snow product using visible, passive microwave and scatterometer satellite data, Int. J. Remote Sens., 32, 1371-1395, https://doi.org/10.1080/01431160903548013, 2011.

Franz, K. J., Hogue, T. S., and Sorooshian, S.: Snow model verification using ensemble prediction and operational benchmarks, J. Hydrometeorol., 9, 1402-1415, https://doi.org/10.1175/2008JHM995.1, 2008.

Fyfe, J. C., Derksen, C., Mudryk, L., Flato, G. M., Santer, B. D., Swart, N. C., Molotch, N. P., Zhang, X., Wan, H., Arora, V. K., Scinocca, J., and Jiao, Y.: Large near-term projected snowpack loss over the western United States, Nat. Commun., 8, 1-7, https://doi.org/10.1038/ncomms14996, 2017.

Gelaro, R., McCarty, W., Suárez, M. J., Todling, R., Molod, A., Takacs, L., Randles, C. A., Darmenov, A., Bosilovich, M. G., Reichle, R., Wargan, K., Coy, L., Cullather, R., Draper, C., Akella, S., Buchard, V., Conaty, A., da Silva, A. M., Gu, W., Kim, G. K., Koster, R., Lucchesi, R., Merkova, D., Nielsen, J. E., Partyka, G., Pawson, S., Putman, W., Rienecker, M., Schubert, S. D., Sienkiewicz, M., and Zhao, B.: The modern-era retrospective analysis for research and applications, version 2 (MERRA2), J. Climate, 30, 5419-5454, https://doi.org/10.1175/JCLID-16-0758.1, 2017 (data available at: https://gmao.gsfc.nasa. gov/reanalysis/MERRA-2/data_access/, last access: 11 February 2021).

Guan, B., Molotch, N. P., Waliser, D. E., Fetzer, E. J., and Neiman, P. J.: The 2010/2011 snow season in California's Sierra Nevada: Role of atmospheric rivers and modes of large-scale variability, Water Resour. Res., 49, 6731-6743, 2013.

Günther, D., Marke, T., Essery, R., and Strasser, U.: Uncertainties in snowpack simulations - assessing the impact of model structure, parameter choice, and forcing data error on point-scale energy balance snow model performance, Water Resour. Res., 55, 2779 2800, https://doi.org/10.1029/2018WR023403, 2019.

Guo, Z., Dirmeyer, P. A., Gao, X., and Zhao, M.: Improving the quality of simulated soil moisture with a multi-model ensemble approach, Q. J. Roy. Meteor. Soc., 133, 731-747, https://doi.org/10.1002/qj.48, 2007.

Ikeda, K., Rasmussen, R., Liu, C., Gochis, D., Yates, D., Chen, F., Tewari, M., Barlage, M., Dudhia, J., Miller, K., Arsenault, K., Grubišić, V., Thompson, G., and Guttman, E.: Simulation of seasonal snowfall over Colorado, Atmos. Res., 97, 462-477, https://doi.org/10.1016/j.atmosres.2010.04.010, 2010.

Jordan, R.: A one-dimensional temperature model for a snow cover: Technical documentation for SNTHERM 89, Tech. Rep. Special Report 91-16, U.S. Army Cold Regions Research and Engineering Laboratory, Hanover, NH, USA, 1991.

Kapnick, S. B. and Delworth, T. L.: Controls of global snow under a changed climate, J. Climate, 26, 5537-5562, https://doi.org/10.1175/JCLI-D-12-00528.1, 2013.

Kapos, V., Rhind, J., Edwards, M., Price, M. F., and Ravilious, C.: Developing a map of the world's mountain forests, in: Forests in sustainable mountain development: A state-of knowledge report for 2000, Task Force on Forests in Sustainable Mountain Development, CAB International, Wallingford, UK, 4-19, 2000.

Kim, E., Gatebe, C., Hall, D., Newlin, J., Misakonis, A., Elder, K., Marshall, H. P., Hiemstra, C., Brucker, L., De Marco, E., and Crawford, C.: NASA's SnowEx campaign: Observing seasonal snow in a forested environment, in: 2017 IEEE International Geoscience and Remote Sensing Symposium (IGARSS), 23-28 July 2017, Fort Worth, TX, USA, IEEE, 1388-1390, 2017.

Kim, R. S., Durand, M., Li, D., Baldo, E., Margulis, S. A., Dumont, M., and Morin, S.: Estimating alpine snow depth by combining multifrequency passive radiance observations with ensemble snowpack modeling, Remote Sens. Environ., 226, 1-15, https://doi.org/10.1016/j.rse.2019.03.016, 2019.

Koster, R. D., Suarez, M. J., Ducharne, A., Stieglitz, M., and Kumar, P.: A catchment-based approach to modeling land surface processes in a general circulation model 1 . Model structure, J. Geophys. Res.-Atmos., 105, 24809-24822, https://doi.org/10.1029/2000JD900327, 2000.

Kumar, S. V., Peters-Lidard, C. D., Tian, Y., Houser, P. R., Geiger, J., Olden, S., Lighty, L., Eastman, J. L., Doty, B., Dirmeyer, P., Adams, J., Mitchell, K., Wood, E. F., and Sheffield, J.: Land information system: An interoperable framework for high resolution land surface modeling, Environ. Model. Softw., 21, 14021415, https://doi.org/10.1016/j.envsoft.2005.07.004, 2006.

Kumar, S. V., Peters-Lidard, C. D., Mocko, D., and Tian, Y.: Multiscale evaluation of the improvements in surface snow simulation through terrain adjustments to radiation, J. Hydrometeorol., 14, 220-232, https://doi.org/10.1175/JHM-D-12-046.1, 2013.

Kumar, S. V, Wang, S., Mocko, D. M., Peters-Lidard, C. D., and Xia, Y.: Similarity assessment of land surface model outputs in the north american land data assimilation system, Water Resour. Res., 53, 8941-8965, https://doi.org/10.1002/2017WR020635, 2017.

Lenderink, G., Buishand, A., and van Deursen, W.: Estimates of future discharges of the river Rhine using two scenario methodologies: direct versus delta approach, Hydrol. Earth Syst. Sci., 11, 1145-1159, https://doi.org/10.5194/hess-11-1145-2007, 2007.

Lettenmaier, D. P., Alsdorf, D., Dozier, J., Huffman, G. J., Pan, M., and Wood, E. F.: Inroads of remote sensing into hydrologic science during the WRR era, Water Resour. Res., 51, 7309-7342, https://doi.org/10.1002/2015WR017616, 2015.

Lundquist, J., Hughes, M., Gutmann, E., and Kapnick, S.: Our skill in modeling mountain rain and snow is bypassing the skill of our observational networks, B. Am. Meteorol. Soc., 100, 2473-2490, https://doi.org/10.1175/BAMS-D-19-0001.1, 2019.

Mahanama, S., Livneh, B., Koster, R., Lettenmaier, D., and Reichle, R.: Soil moisture, snow, and seasonal streamflow fore- 
casts in the United States, J. Hydrometeorol., 13, 189-203, https://doi.org/10.1175/JHM-D-11-046.1, 2012.

Marshall, A. M., Abatzoglou, J. T., Link, T. E., and Tennant, C. J.: Projected Changes in Interannual Variability of Peak Snowpack Amount and Timing in the Western United States, Geophys. Res. Lett., 46, 8882-8892, https://doi.org/10.1029/2019GL083770, 2019.

Matheson, J. E. and Winkler, R. L.: Scoring rules for continuous probability distributions, Manage. Sci., 22, 1087-1096, https://doi.org/10.1287/mnsc.22.10.1087, 1976.

Meromy, L., Molotch, N. P., Link, T. E., Fassnacht, S. R., and Rice, R.: Subgrid variability of snow water equivalent at operational snow stations in the western USA, Hydrol. Process., 27, 23832400, https://doi.org/10.1002/hyp.9355, 2013.

Mitchell, K. E., Lohmann, D., Houser, P. R., and Wood, E. F.: The multi-institution North American Land Data Assimilation System (NLDAS): Utilizing multiple GCIP products and partners in a continental distributed hydrological modeling system, J. Geophys. Res., 109, D07S90, https://doi.org/10.1029/2003JD003823, 2004.

Molod, A., Takacs, L., Suarez, M., and Bacmeister, J.: Development of the GEOS-5 atmospheric general circulation model: evolution from MERRA to MERRA2, Geosci. Model Dev., 8, 1339-1356, https://doi.org/10.5194/gmd-8-1339-2015, 2015.

Molteni, F., Buizza, R., Palmer, T. N., and Petroliagis, T.: The ECMWF ensemble prediction system: Methodology and validation, Q. J. Roy. Meteor. Soc., 122, 73-119, https://doi.org/10.1256/smsqj.52904, 1996 (data available at: https://www.ecmwf.int/en/forecasts/datasets, last access: 5 February 2021).

Mudryk, L. R., Derksen, C., Kushner, P. J., and Brown, R.: Characterization of northern hemisphere snow water equivalent datasets, 1981-2010, J. Climate, 28, 8037-8051, https://doi.org/10.1175/JCLI-D-15-0229.1, 2015.

Murphy, J. M., Sexton, D. M. H., Barnett, D. H., Jones, G. S., Webb, M. J., Collins, M., and Stainforth, D. A.: Quantification of modelling uncertainties in a large ensemble of climate change simulations, Nature, 430, 768-772, https://doi.org/10.1038/nature02771, 2004.

National Academies of Sciences, Engineering, and Medicine: Thriving on Our Changing Planet: A Decadal Strategy for Earth Observation from Space, The National Academies Press, Washington, D.C., USA, 2018.

Niu, G.-Y., Yang, Z.-L., Mitchell, K. E., Chen, F., Ek, M. B., Barlage, M., Kumar, A., Manning, K., Niyogi, D., Rosero, E., Tewari, M., and Xia, Y.: The community Noah land surface model with multiparameterization options (Noah-MP): 1. Model description and evaluation with localscale measurements, J. Geophys. Res.-Atmos., 116, D12109, https://doi.org/10.1029/2010JD015139, 2011.

Nolin, A. W.: Recent advances in remote sensing of seasonal snow, J. Glaciol., 56, 1141-1150, https://doi.org/10.3189/002214311796406077, 2010.

Pavelsky, T. M., Kapnick, S., and Hall, A.: Accumulation and melt dynamics of snowpack from a multiresolution regional climate model in the central Sierra Nevada, California, J. Geophys. Res.Atmos., 116, D16115, https://doi.org/10.1029/2010JD015479, 2011.
Peters-Lidard, C. D., Houser, P. R., Tian, Y., Kumar, S. V., Geiger, J., Olden, S., Lighty, L., Doty, B., Dirmeyer, P., Adams, J., Mitchell, K., Wood, E. F., and Sheffield, J.: High-performance earth system modeling with NASA/GSFC's Land Information System, Innovations in Systems and Software Engineering, 3, 157-165, https://doi.org/10.1007/s11334-007-0028-x, 2007.

Raleigh, M. S., Livneh, B., Lapo, K., and Lundquist, J. D.: How does availability of meteorological forcing data impact physically based snowpack simulations?, J. Hydrometeorol., 17, 99120, https://doi.org/10.1175/JHM-D-14-0235.1, 2016.

Raup, B., Racoviteanu, A., Khalsa, S. J. S., Helm, C., Armstrong, R., and Arnaud, Y.: The GLIMS geospatial glacier database: A new tool for studying glacier change, Global Planet. Change, 56, 101-110, https://doi.org/10.1016/j.gloplacha.2006.07.018, 2007.

Reichle, R. H., Draper, C. S., Liu, Q., Girotto, M., Mahanama, S. P. P., Koster, R. D., and De Lannoy, G. J. M.: Assessment of MERRA-2 land surface hydrology estimates, J. Climate, 30, 2937-2960, 2017.

Robinson, D. A. and Kukla, G.: Maximum surface albedo of seasonally snow-covered lands in the northern hemisphere, J. Clim. Appl. Meteorol., 24, 402-411, https://doi.org/10.1175/15200450(1985)024<0402:MSAOSS>2.0.CO;2, 1985.

Rutter, N., Essery, R., Pomeroy, J., Altimir, N., Andreadis, K., Baker, I., Barr, A., Bartlett, P., Boone, A., Deng, H., Douville, H., Dutra, E., Elder, K., Ellis, C., Feng, X., Gelfan, A., Goodbody, A., Gusev, Y., Gustafsson, D., HellströM, R., Hirabayashi, Y., Hirota, T., Jonas, T., Koren, V., Kuragina, A., Lettenmaier, D., Li, W.-P., Luce, C., Martin, E., Nasonova, O., Pumpanen, J., Pyles, R. D., Samuelsson, P., Sandells, M., SchäDler, G., Shmakin, A., Smirnova, T. G., StäHli, M., StöCkli, R., Strasser, U., Su, H., Suzuki, K., Takata, K., Tanaka, K., Thompson, E., Vesala, T., Viterbo, P., Wiltshire, A., Xia, K., Xue, Y., and Yamazaki, T.: Evaluation of forest snow processes models (SnowMIP2), J. Geophys. Res.-Atmos., 114, D06111, https://doi.org/10.1029/2008JD011063, 2009.

Ryberg, K. R., Akyüz, F. A., Wiche, G. J., and Lin, W.: Changes in seasonality and timing of peak streamflow in snow and semi-arid climates of the north-central United States, 1910-2012, Hydrol. Process., 30, 1208-1218, https://doi.org/10.1002/hyp.10693, 2016.

Skamarock, W. C., Klemp, J. B., Dudhia, J., Gill, D. O., Barker, D. M., Wang, W., and Powers, J. G.: A description of the Advanced Research WRF version 3. Technical Note 475., Note NCAR/TN4751STR, 113 pp., https://doi.org/10.5065/D68S4MVH, 2008.

Stewart, I. T., Cayan, D. R., and Dettinger, M. D.: Changes toward earlier streamflow timing across western North America, J. Climate, 18, 1136-1155, https://doi.org/10.1175/JCLI3321.1, 2005.

Stielstra, C. M., Lohse, K. A., Chorover, J., McIntosh, J. C., BarronGafford, G. A., Perdrial, J. N., Litvak, M., Barnard, H. R., and Brooks, P. D.: Climatic and landscape influences on soil moisture are primary determinants of soil carbon fluxes in seasonally snow-covered forest ecosystems, Biogeochemistry, 123, 447465, https://doi.org/10.1007/s10533-015-0078-3, 2015.

Takala, M., Luojus, K., Pulliainen, J., Derksen, C., Lemmetyinen, J., Kärnä, J.-P., Koskinen, J., and Bojkov, B.: Estimating northern hemisphere snow water equivalent for climate research through assimilation of space-borne radiometer data and groundbased measurements, Remote Sens. Environ., 115, 3517-3529, https://doi.org/10.1016/j.rse.2011.08.014, 2011. 
Vuyovich, C. M., Jacobs, J. M., and Daly, S. F.: Comparison of passive microwave and modeled estimates of total watershed SWE in the continental United States, Water Resour. Res., 50, 90889102, https://doi.org/10.1002/2013WR014734, 2014.

Westerling, A. L., Hidalgo, H. G., Cayan, D. R., and Swetnam, T. W.: Warming and earlier spring increase Western U.S. forest wildfire activity, Science, 313, 940-943, https://doi.org/10.1126/science.1128834, 2006.

Wrzesien, M. L., Pavelsky, T. M., Kapnick, S. B., Durand, M. T., and Painter, T. H.: Evaluation of snow cover fraction for regional climate simulations in the Sierra Nevada, Int. J. Climatol., 35, 2472-2484, 2015.

Wrzesien, M. L., Durand, M. T., Pavelsky, T. M., Howat, I. M., Margulis, S. A., and Huning, L. S.: Comparison of methods to estimate snow water equivalent at the mountain range scale: A case study of the California Sierra Nevada, J. Hydrometeorol., 18, 1101-1119, https://doi.org/10.1175/JHM-D-16-0246.1, 2017.

Wrzesien, M. L., Durand, M. T., Pavelsky, T. M., Kapnick, S. B., Zhang, Y., Guo, J., and Shum, C. K.: A new estimate of North American mountain snow accumulation from regional climate model simulations, Geophys. Res. Lett., 45, 1423-1432, 2018.

Xia, Y., Mitchell, K., Ek, M., Sheffield, J., Cosgrove, B., Wood, E., Luo, L., Alonge, C., Wei, H., Meng, J., Livneh, B., Lettenmaier, D., Koren, V., Duan, Q., Mo, K., Fan, Y., and Mocko, D.: Continental-scale water and energy flux analysis and validation for the North American Land Data Assimilation System project phase 2 (NLDAS-2): 1. Intercomparison and application of model products, J. Geophys. Res.-Atmos., 117, D03109, https://doi.org/10.1029/2011JD016048, 2012.
Yang, Z. L., Niu, G. Y., Mitchell, K. E., Chen, F., Ek, M. B., Barlage, M., Longuevergne, L., Manning, K., Niyogi, D., Tewari, M., and Xia, Y.: The community Noah land surface model with multiparameterization options (Noah-MP): 2. Evaluation over global river basins, J. Geophys. Res.-Atmos., 116, D12110, https://doi.org/10.1029/2010JD015140, 2011.

Yoon, Y., Kumar, S. V., Forman, B. A., Zaitchik, B. F., Kwon, Y., Qian, Y., Rupper, S., Maggioni, V., Houser, P., Kirschbaum, D., Richey, A., Arendt, A., Mocko, D., Jacob, J., Bhanja, S., and Mukherjee, A.: Evaluating the uncertainty of terrestrial water budget components over high mountain asia, Front. Earth Sci., 7, 120, https://doi.org/10.3389/feart.2019.00120, 2019.

Zeng, X., Broxton, P., and Dawson, N.: Snowpack change from 1982 to 2016 over conterminous United States, Geophys. Res. Lett., 45, 12940-12947, https://doi.org/10.1029/2018GL079621, 2018. 